Biogeosciences Discuss., 7, 5517-5555, 2010

www.biogeosciences-discuss.net/7/5517/2010/

doi:10.5194/bgd-7-5517-2010

(C) Author(s) 2010. CC Attribution 3.0 License.

\title{
Impact of climate and land use/cover changes on the carbon cycle in China (1981-2000): a system-based assessment
}

Z. Gao ${ }^{1,2}$, W. Gao ${ }^{2}$, and N.-B. Chang ${ }^{3}$

${ }^{1}$ Institute of Geographical Sciences and Natural Resources Research, Chinese Academy of Sciences, Beijing, 100101, China

${ }^{2}$ USDA UV-B Monitoring and Research Program and Center of Remote Sensing and Modeling for Agricultural Sustainability, Natural Resource Ecology Laboratory, Colorado State University, Fort Collins, CO 80521, USA

${ }^{3}$ Department of Civil, Environmental, and Construction Engineering, University of Central Florida, Orlando, FL, 32816, USA

Received: 21 May 2010 - Accepted: 21 June 2010 - Published: 19 July 2010

Correspondence to: Z. Gao (gaoland@gmail.com)

Published by Copernicus Publications on behalf of the European Geosciences Union.

Impact of climate and land use/cover changes on the carbon cycle in China

Z. Gao et al.

Title Page

Abstract

Conclusions

Tables

14

4

Back

Full Screen / Esc

Printer-friendly Version

Interactive Discussion 


\section{Abstract}

In China, cumulative changes in climate and land use/land cover (LULC) from 1981 to 2000 had collectively affected the net productivity in the terrestrial ecosystem and thus the net carbon flux, both of which are intimately linked with the global carbon 5 cycle. This paper represents the first national effort of its kind to systematically investigate the impact of changes of LULC on carbon cycle with high-resolution dynamic LULC data at the decadal scale (1990s and 2000s). The CEVSA was applied and driven by high resolution LULC data retrieved from remote sensing and climate data collected from two ground-based meteorological stations. In particular, it allowed us ( primary productivity (NPP), vegetation carbon (VEGC) storage, soil carbon (SOC) storage, heterotrophic respiration (HR), and net ecosystem productivity (NEP)) and carbon storage from 1981 to 2000 . Simulations generally agree with output from other models and results from bookkeeping approach. Based on these simulations, temporal and spatial variations in carbon storage and fluxes in China may be confirmed and we are able to relate these variations to climate variability during this period for detailed analyses to show influences of the LULC and environmental controls on NPP, NEP, HR, SOC, and VEGC. Overall, the increases in NPP were greater than $\mathrm{HR}$ in most of the time due to the effect of global warming with more precipitation in China from 1981 to 2000 . With this trend, the NEP remained positive during that period, resulting in the net increase of total amount of carbon being stored by about $0.296 \mathrm{PgC}$ within the 20-years time frame. Because the climate effect was much greater than that of changes of LULC, the total carbon storage in China actually increased by about $0.17 \mathrm{PgC}$ within the 20 years. Such findings will contribute to the generation of control policies of carbon emissions under global climate change.
BGD

$7,5517-5555,2010$

\section{Impact of climate and land use/cover changes on the carbon cycle in China}

Z. Gao et al.

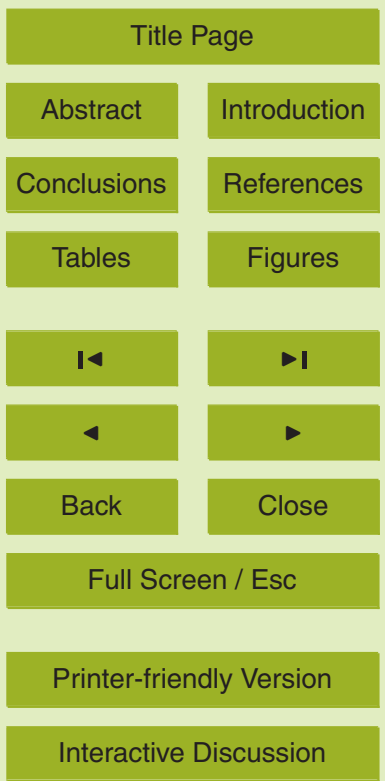




\section{Introduction}

Many problems associated with ecosystem conservation have roots in anthropogenic disruptions of natural biogeochemical cycles such as those of water and carbon. The driving mechanism associated with the physical climate system and social-economic 5 system collectively plays an important role in biogeochemical cycle research. Understanding of the mechanisms of these interactions via a holistic assessment by way of earth system modeling would be equally as important as studies of individual dynamic processes occurring in specific ecosystems (Cao et al., 1998a; DeFries et al., 1999; Fang et al., 2001; Houghton et al., 1999; Melillo et al., 1993; Pacala et al., 2001; Peng et al., 2009; Stephen et al., 1995).

The effects of climatic change on the ecosystem's carbon cycle involve impacts on plant photosynthesis, respiration, and decomposition of soil organic carbon. Landuse change directly affects the distribution and structure of terrestrial ecosystems and changes the carbon storage and fluxes in terrestrial ecosystems. Land use/cover change (LUCC) can affect energy flow within biogeochemical and hydrological cycling in terrestrial ecosystems through altering land surface and species composition (Cao et al., 1998b; Braswell et al.1997; Bousquet et al., 1997; Houghton et al., 1987, 1991; McGuire et al., 2001). Ecosystem carbon cycling responds differently to various types of LUCC showing a pattern of $\mathrm{CO}_{2}$ release into the atmosphere when changes occur from a high-biomass forest to low-biomass grassland, cropland or urban area. The terrestrial ecosystem plays a dual role in carbon uptake/release effects in the global carbon cycle, and it is an important part of the interaction between human activity and climate change. The problem of LUCC effecting carbon cycling in the terrestrial ecosystem was one of the most worrisome environmental problems concerned by scientists, land managers and policy makers in many interdisciplinary studies in the past two decades (Houghton et al., 2000, 2003a,c, 2005; Caspersen et al., 2000; Feddema et al., 2005; John, et al., 2000; Klein, 2001; Klein et al., 2004; Ramankutty, et al., 1998; Schimel et al., 2000, 2001; Vleeshouwers et al., 2002; Strassmann, et al., 2008; Guo,
BGD

$7,5517-5555,2010$

\section{Impact of climate and land use/cover changes on the carbon cycle in China}

Z. Gao et al.

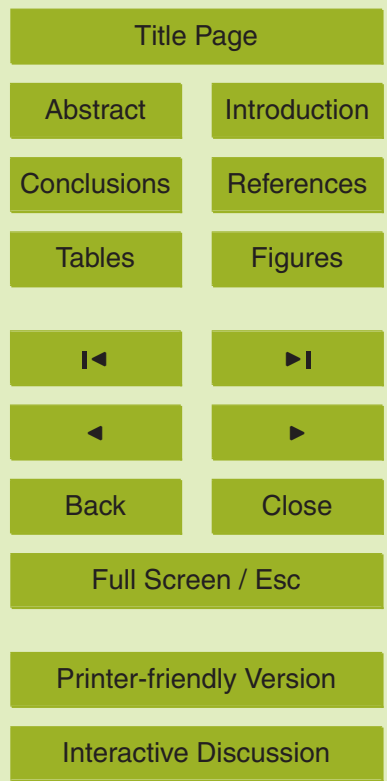


et al., 2002; Phillips, et al., 1998; Ramankutty et al., 1999). With its immense land resources, the climate and ecosystem in China are complex and diverse, and the degree of LUCC has varied widely from region to region in the past two decades resulting in an important impact on the national carbon cycle (Liu et al., 2005a,b; Li et al., 2003, 5 2004; Sha, 2002).

For this reason, a number of studies were carried out at the national level for estimating China's net primary productivity (NPP) (Jiang et al., 1999; Ni et al., 2001; Ni, 2003; Fang et al., 2003; Piao et al., 2005; Zhao and Zhou, 2005), forest biomass (Fang et al., 1998, 2001; Feng et al., 1999; Li et al., 2004; Pan et al., 2004), SOC storage (Fang 10 et al., 1996; Wang et al., 2003; Wu et al., 2003a,b), possible responses to past climate change (Peng and Apps, 1997), interannual climate variability (Cao et al., 2003; Piao et al., 2003, 2005), and future movement of climate change (Xiao et al., 1998; Gao et al., 2000; Ni et al., 2001). Recent estimates of forest biomass carbon in China suggested that Chinese forest ecosystems have been acting as a carbon sink during the 15 past decades (Fang et al., 2001, Houghton, et al., 2003, Ge et al., 2008). For instance, Xiao et al. (1998) estimated the annual average of China's NPP to be about 3.65 Pg C using the terrestrial ecosystem model (TEM). Cao et al. (2003) simulated carbon flux changes in China with a model of carbon exchange between vegetation, soil, and atmosphere (CEVSA) for the period of 1981-2000. It is estimated that the NPP was in the range of $2.86-3.21 \mathrm{PgC}$ and soil heterotrophic respiration $(\mathrm{HR})$ was in the range of 2.89-3.21 Pg C in China within that 20 years. Fang et al. (2001) analyzed the forest biomass changes over the past 50 years in China based on the national forest inventory data. The results revealed that human activities such as afforestation had led to an increase in forest carbon storage of $0.45 \mathrm{Pg} \mathrm{C}$ from the mid-1970s to 2000 . Wang et al. (2003) analyzed the SOC storage in China using the initial and the second National Soil Survey data, and found out that the SOC storage in China was $93 \mathrm{Pg} \mathrm{C}$ in the 1960 s and $92 \mathrm{PgC}$ in the 1980s, resulting in a net decrease of $1 \mathrm{Pg} \mathrm{C}$ in a 20 -years time frame. Wu et al. (2003a) also analyzed the impacts of land use on soil carbon (SOC) in China using the second national soil survey data solely and they pointed out
BGD

$7,5517-5555,2010$

\section{Impact of climate and land use/cover changes on the carbon cycle in China}

Z. Gao et al.

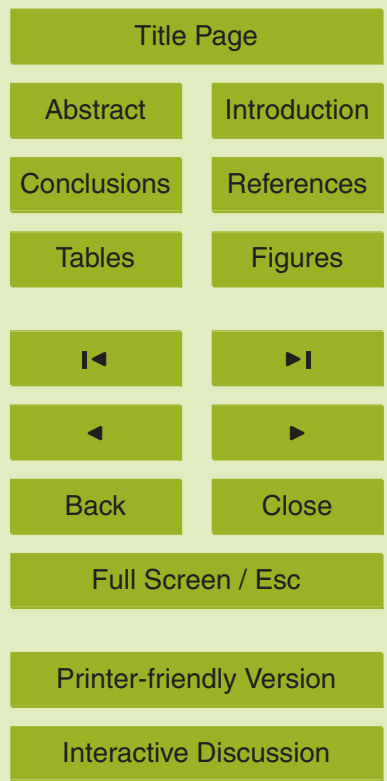


that the SOC in China was decreased by $7.1 \mathrm{Pg} \mathrm{C}$, while SOC storage was reduced by $0.8 \mathrm{~kg} \mathrm{C} / \mathrm{m}^{2}$ because of the impact of LUCC.

Between 1981 and 2000, the climate and land use in different regions in China simultaneously experienced changes. Global warming was salient with regional variations.

5 Sha et al. (2002) found that the climate of Northern China became colder, while Southern China became warmer in the study period. On average, the rate of change of global temperature was $0.40^{\circ} \mathrm{C}$ in Northern China and $0.34^{\circ} \mathrm{C}$ in Southern China. The temperature between 1981 and 2000 in northern arid areas was higher than the average temperature of the twentieth century by $1{ }^{\circ} \mathrm{C}$ Liu et al. $(2005 a, b)$ analyzed the 10 LUCC with Landsat remote sensing data over the period from 1990-2000 in China and found out that the LUCC had significant regional differences due to the impacts of land management policy and economic development. Within the 1990s, farmland increased in Northern China and decreased in Southern China, while the total area of farmland increased. Forested land and grassland decreased gradually and constructed land ex15 panded continually (Liu et al., 2005a,b). This paper represents the first national effort of its kind to systematically investigate the impact of LUCC on carbon cycle with highresolution dynamic land use and land cover (LULC) data at the decadal scale (1990s and 2000s). In particular, CEVSA model was employed to simulate carbon fluxes (net primary productivity (NPP), heterotrophic respiration (HR) and net ecosystem productivity (NEP)) and carbon storage (vegetation carbon (VEGC) storage and soil carbon (SOC) storage) from 1981 to 2000 in order to differentiate the individual impact of LUCC on carbon fluxes and carbon storage given the possible climate change scenarios.

\section{Materials and methods}

In order to estimate the impacts of climate and LUCC on the carbon cycle of the ecosys25 tem in China, the CEVSA model was employed to simulate changes of NPP, vegetation carbon, HR, soil carbon, and NEP. The NEP is equal to the difference between NPP and HR, which can be viewed as either the carbon sink if NPP is larger than the HR or

\section{BGD}

$7,5517-5555,2010$

\section{Impact of climate and land use/cover changes on the carbon cycle in China}

Z. Gao et al.

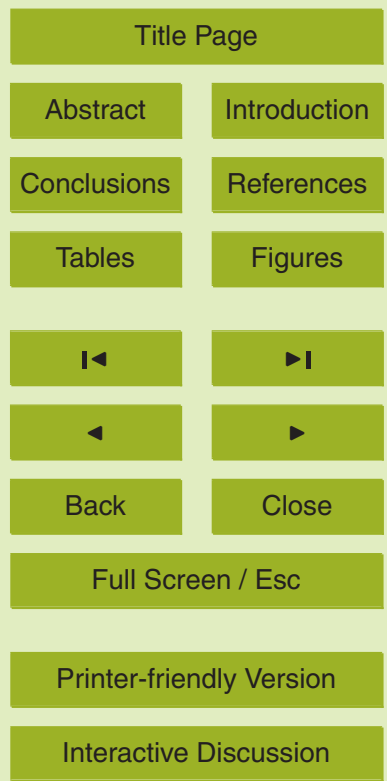


the carbon source if the NPP is smaller than the HR. With the substantially quantified NEP information using the CEVSA model, we were able to test two hypotheses linking two different quantitative impacts on the carbon cycle. The two hypotheses are: 1) the LUCC encountered in China from 1981 to 2000 mildly decreased the carbon storage; 5 2) the climate change in association with the increase of precipitation encountered in China from 1981 to 2000 increased the carbon storage to some extent. It was envisioned that the cumulative carbon storage and release could eventually lead to a net effect of carbon sink based on these two hypotheses holistically.

\subsection{The CEVSA model}

10 The carbon cycle of the terrestrial ecosystem is driven through the processes of photosynthesis, autotrophic respiration, litter production, and soil respiration (HR). These processes are controlled by the eco-physiological characteristics of biomes (e.g., photosynthetic pathway, leaf form, and phenology ) and by environmental conditions (e.g., radiation, temperature, availability of water, and nutrients). To couple these biological and environmental controls over ecosystem carbon fluxes, CEVSA includes the following three modules (Fig. 1): 1) The biophysical module calculates the transfer of radiation, water, and heat to determine canopy conductance, evapotranspiration, and soil moisture; 2) The plant growth module describes photosynthesis, autotrophic respiration, and carbon allocation among plant organs, leaf area index (LAI), and litter 20 production; 3) The biogeochemical module simulates the transformation and decomposition of organic materials and nitrogen inputs and outputs to soils. Detailed descriptions of the model are given in Cao and Woodward (1998a,b). The key processes are described in the literature (Cao et al., 1998a,b, 2004, 2005; Woodward et al., 1995).

\subsection{Land use/cover change derived from the Landsat/TM images}

25 The 1:100 000 land cover datasets in China applied in this study were generated based on the Landsat Thematic Mapper (TM) images. Land-use datasets with 1-km resolu-
BGD

7, 5517-5555, 2010

\section{Impact of climate and land use/cover changes on the carbon cycle in China}

Z. Gao et al.

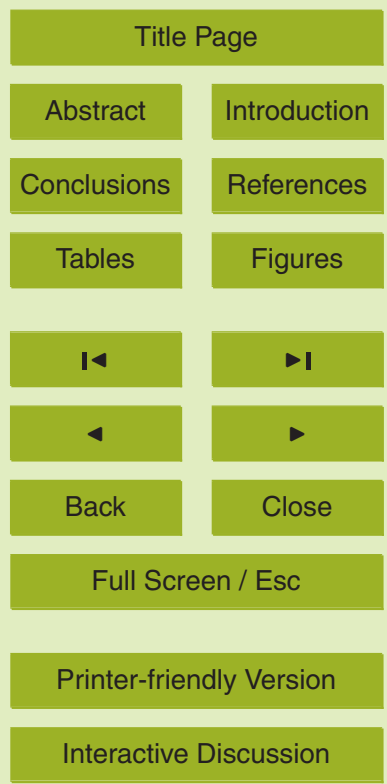


tion in 1990 and 2000 were created. For each time period in the 1980s and 1990s, the total number of scenes to cover the entire country was more than 500 . Visual interpretation and digitization of Landsat TM images at the scale of 1:100 000 were carried out to generate the thematic maps of land cover under technical support from Intergraph

5 MGE (Modular GIS Environment) software. A hierarchical classification system of 25 land-cover classes was applied to support the analysis in which six aggregated classes of land cover including croplands, woodlands, grasslands, water bodies, unused land and built-up areas were categorized. The extraction of LUCC information was made possible by comparing the two derived LULC maps associated with 1990 and 2000, 10 respectively (Liu et al., 2005a). Besides, vegetation cover was further differentiated to support the required vegetation classification system used in the CEVSA model. To achieve this goal, this study used the Advanced Very High Resolution Radiometer (AVHRR) data and other relevant variables such as temperature and elevation (Digital Elevation Model, DEM) to investigate vegetation distribution associated with 1990 15 and 2000, respectively via the use of a supervised classification procedure (Liu et al., 2005a).

\subsection{The CEVSA application}

The CEVSA model was driven by meteorological data with a resolution of $10 \mathrm{~km}$ over a 10-day period. The meteorological datasets were collected by 671 weather stations.

20 The parameters of relevance include daily precipitation, temperature, cloud cover, atmospheric pressure, and humidity. First, the daily meteorological data was processed by deriving the mean value over each 10-day period and then, to account for effects of longitude, latitude, and elevation, a spline function for interpolation was used to populate the meteorological data over all grids with a spatial resolution of $10 \mathrm{~km}$ based on these temporally averaged point measurements. The soil texture data were derived from the National Soil Survey database (1979 1994). The LULC database is the same as we introduced above as the Chinese Resources and Environment Remote-sensing Database created by the Chinese Academy of Sciences. Figure 2a summarizes the

BGD

7, 5517-5555, 2010

\section{Impact of climate and land use/cover changes on the carbon cycle in China}

Z. Gao et al.

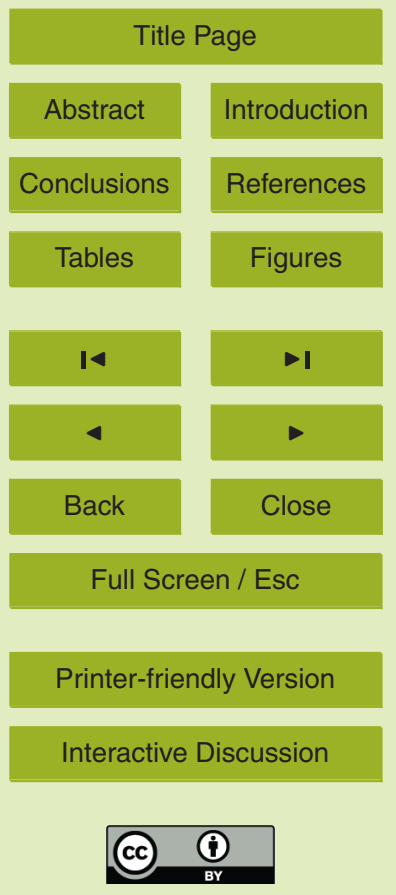


LULC in the 1990s whereas Fig. $2 b$ shows the LUCC between the 1980s and 1990s.

The running of the CEVSA model can be divided into equilibrium and dynamic stages. The equilibrium simulation was designed to use average meteorological data and a distinct land cover to run CEVSA until equilibrium was reached. Based on the 5 equilibrium status, CEVSA was run using the actual meteorological data (Cao et al., 1998a,b). The specific simulations can be described as follows: 1) With LULC data of 1990 and the average meteorological data for the period 1971-1990, the CEVSA model was run to equilibrium (i.e., the variation of the major state variable of the ecosystem). For example, the changes in vegetation and soil organic carbon (SOC), nitrogen 10 storage, and moisture content of the soil are less than 1\%, and NPP, litter production, and HR are equivalent. Then, the CEVSA was run by using actual meteorological data for every 10 days from 1971 to 2000. 2) On the basis of the land cover of 2000, the CEVSA model was run to the equilibrium state with the average climate data for the period 1981-2000, and was then run using actual meteorological data of every 10-day 15 period from 1981 to 2000.

In order to estimate the individual impact of climate changes on the carbon cycle, in the first scenario we assumed that there were no changes of LULC within these two decades. Therefore, we used the results of the dynamic simulation run from 1981 to 2000 with the aid of the LULC of 1990 to analyze the impacts of climate change, and compared the changes of the average values of carbon storage and flux (e.g., NPP, $\mathrm{HR}$, NEP, and vegetation and carbon storage of soil) of the ecosystem from 1990 to 2000. Similarly, in the second scenario, we assumed no climate change to isolate the impacts of LUCC on carbon storage and flux. The difference between the average values of carbon storage and flux associated with the two LULC maps related to $1980 \mathrm{~s}$

\subsection{Modeling performance of the CEVSA and bookkeeping model}

The CEVSA model has been calibrated and validated to simulate soil carbon, vegetation carbon, NPP, HR, NEP (Cao et al., 1998a,b, 2001, 2002, 2005). To assess

BGD

$7,5517-5555,2010$

\section{Impact of climate and land use/cover changes on the carbon cycle in China}

Z. Gao et al.

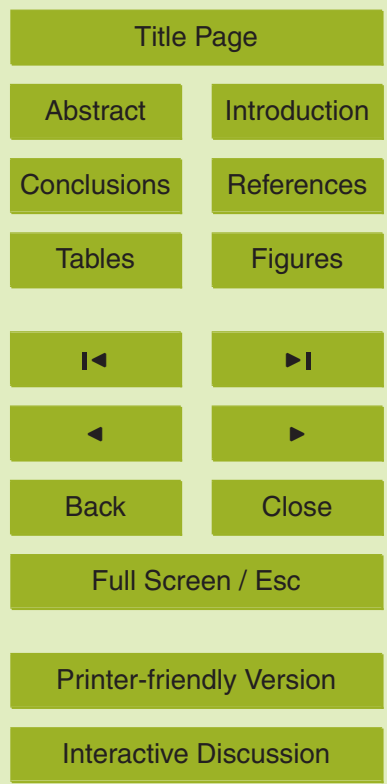


the model performance on simulating NPP, HR and NEP, Gu et al. (2006) compared the $\mathrm{CO}_{2}$ and water flux between the data simulated by the CEVSA and the measurements collected by the eddy covariance tower in a sub-tropical coniferous forest and Gao et al. (2008) compared the actual NPP with corresponding values simulated by 5 using three models including the CEVSA, CASA, and the GLOPEM. With such a baseline for China's total biomass production, model performance could be evaluated with respect to various criteria. The CEVSA model has been widely used worldwide to study the response of carbon cycling in the terrestrial ecosystem to climate change and LUCC. With the aid of the prescribed GCM scenarios of $\mathrm{CO}_{2}$ and climate change, 10 Cao et al. (1998) used the CEVSA model to perform simulations at a spatial resolution of 2.58 latitude 3.758 longitude and a time step of one month, allowing the authors to study the dynamic responses of terrestrial ecosystem carbon cycling to global climate change. With the CEVSA model, Cao et al. $(1998,2002,2005)$ investigated the responses of global NPP, HR and NEP to atmospheric $\mathrm{CO}_{2}$ increases and climate variimpacts of LUCC and climate changes on NPP, VEGC storage, HR, SOC storage and NEP in the cropping-grazing transition zone of China. We therefore follow the CEVSA model to conduct our analysis.

The bookkeeping model that can be integrated with the CEVSA model to smooth out the holistic assessment of NEP with respect to LUCC was first used by Houghton et al. (1983, 1987, 1991), Houghton (1999) and Houghton and Hackler (1999) to study the carbon sources and sinks resulting from land use and land management in nine regions of the world. Calculations were carried out based on two types of data: one concerns land use changes and the other is the data of carbon storage density changes caused by land use and land management. Annual per hectare changes in vegetation and soil following a previous land-use change were defined in the model for different types of ecosystems and land uses. The model tracks the areas of different land uses and the amounts of carbon held in live vegetation, slash, wood products, and soil. Changes in the pools from one year to the next define the net annual flux of carbon

\section{BGD}

$7,5517-5555,2010$

\section{Impact of climate and land use/cover changes on the carbon cycle in China}

Z. Gao et al.

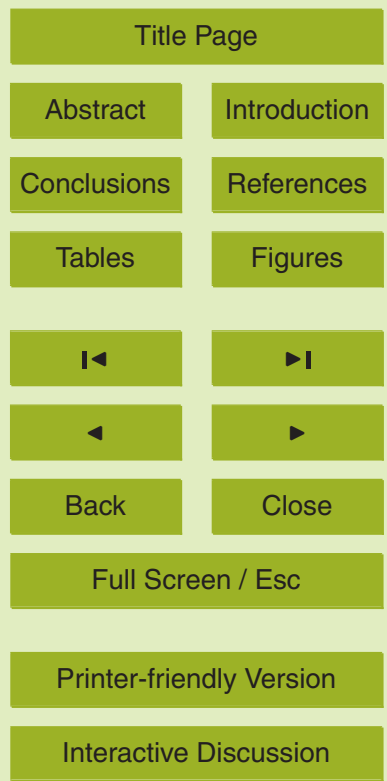


between land and the atmosphere. The time step is yearly. It is considered as an effective method to quantitatively describe the entire cycling of carbon in each carbon pool from "cradle" to "grave". The model calculates the flux of carbon that is attributable to direct human activity. It does not include the effects on carbon storage of increased 5 atmospheric $\mathrm{CO}_{2}$, increased deposition of nitrogen, or changes in climate (Houghton et al., 1983, 1999; Houghton and Hackler, 1995). Thus, after running the CEVSA model, we followed this bookkeeping approach to estimate the impact of LUCC and climate changes on the terrestrial carbon storage and flux in China for the period of 1981-2000.

\section{Results and discussion}

\subsection{The impacts of climate changes on the carbon storage and carbon flux}

China is located at the eastern edge of the Eurasian continent and faces the Pacific in the east. The monsoon climate is prevalent over China's mainland due to the unique pattern of sea-land interactions leading to larger periodical changes in precipitation interannually. The average precipitation from 1981 to 2000 was $623 \mathrm{~mm} / \mathrm{y}$ and the annual variation of precipitation was $4.4 \%$. The average rainfall was $620.5 \mathrm{~mm} / \mathrm{y}$ for the time period 1981 to 1990 and $625.6 \mathrm{~mm} / \mathrm{y}$ for the time period 1991-2000 (Sha et al., 2002). A mild increasing trend of precipitation in recent years can be characterized according to Fig. 3. As a consequence, the increase of the precipitation rate was $0.65 \mathrm{~mm} / \mathrm{y}$ in the study time period.

The spatial distribution of precipitation varied considerably from 1981 to 2000 . The areas with an average annual rainfall greater than $800 \mathrm{~mm}$ accounted for $27 \%$ of the whole nation. They were mainly around the south of the Huaihe River and hilly areas of South China. The areas with an average annual rainfall between 400 and $800 \mathrm{~mm}$ accounted for $29 \%$ of the entire nation. They were mainly around Northeast China, North China, and the eastern part of the Qinghai-Tibet Plateau. Those areas with an
BGD

7, 5517-5555, 2010

\section{Impact of climate and land use/cover changes on the carbon cycle in China}

Z. Gao et al.

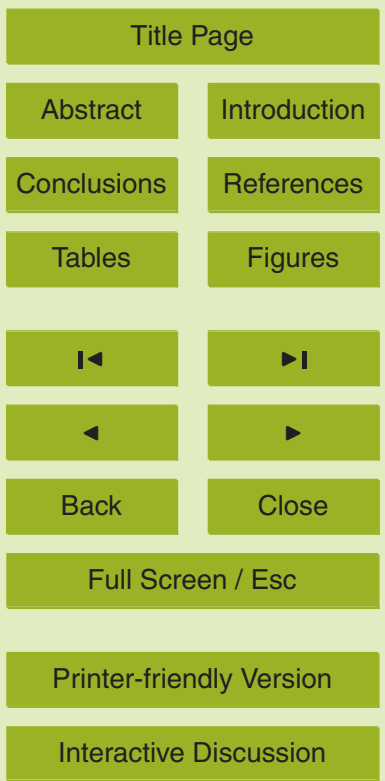


average annual rainfall smaller than $400 \mathrm{~mm}$ accounted for $44 \%$ of the nation. They were mainly around the western areas of Inner Mongolia, Xinjiang, and Qinghai mostly within arid and semiarid regions.

The annual changes in temperature were also very large within the same time pe5 riod. The annual average temperature was $6.54^{\circ} \mathrm{C}$, and the annual rate of temperature increase was $4.66 \%$. Figure 3 confirms this tendency with an average annual increase of $0.055^{\circ} \mathrm{C}$. The average temperature in the first ten years was $6.3^{\circ} \mathrm{C}$ from 1981 to 1990 , whereas it became $6.77^{\circ} \mathrm{C}$ in second ten years from 1991 to 2000 . The decadal change of annual average temperature was as high as $0.47^{\circ} \mathrm{C}$. Table 1 includes this in10 formation against the corresponding changes of carbon flux. The areas with an annual average temperature greater than $10^{\circ} \mathrm{C}$ accounted for $40 \%$ of the entire nation. They were mainly around from the south of the Huaihe River to the east of the Qinghai-Tibet Plateau, and to the Tarim Basin area. The areas with an annual average temperature less than $0{ }^{\circ} \mathrm{C}$ only accounted for $14 \%$ of the entire nation. They were mainly around 15 the Qinghai-Tibet Plateau and Daxinganling areas. About $46 \%$ of the entire nation was at an annual average temperature between $1^{\circ} \mathrm{C}$ and $10^{\circ} \mathrm{C}$, which was mainly located in these provinces north along the Huaihe River.

As attested by Fig. 4, the NPP increased during the 1980s and 1990s at an annual rate of $0.006 \mathrm{PgC}$ per year in China. Yet such a trend of NPP increase for the period of 1981-1990 was not salient given that the increase of NPP was only $0.004 \mathrm{Pg}$ C per year in the first 10 years. The trend of annual NPP increase from 1991 to 2000 was $0.014 \mathrm{Pg} C$ per year, which was quite significant. The continued increase of NPP over a 20-year period led to an increase of VEGC of $0.007 \mathrm{Pg} \mathrm{C}$ per year. It is worth pointing out that NPP and precipitation were positively correlated $(r=0.71, p<0.01)$. But NPP and temperature were not strongly correlated $(r=0.36, p<0.01)$. As can be seen in Fig. 3, there were upward trends in both temperature and precipitation, especially over the second 10-year period. Figure 4 further confirms that many areas also experienced an increase of NPP and HR in the same time period. But the interesting question left unanswered was the interactions between VEGC and HR. Figure 5 and Table 1 col-
BGD

$7,5517-5555,2010$

\section{Impact of climate and land use/cover changes on the carbon cycle in China}

Z. Gao et al.

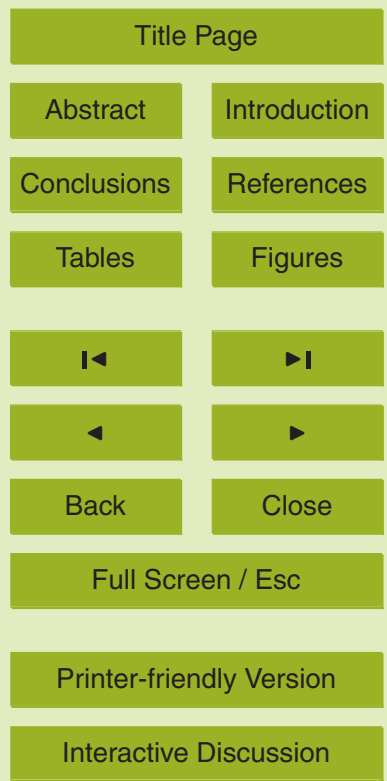


lectively answer the question in regard to the long-term changes of vegetation carbon, SOC and NEP. Note that the SOC reached a peak in 1996. This clearly shows that NEP was negative by the end of 1990s while VEGC became larger over this time period.

With this finding temporally, it would be interested in knowing more about the spatial 5 distribution of these parameters in relation to the carbon cycle. Whereas Fig. 6 shows the yearly snapshot of the carbon storage and flux, Fig. 7 displays the long-term situation of the annual carbon storage and flux averaged over the 20-year time frame. The areas in which an increase of NPP was observed due to climate change over the study period accounted for $21 \%$ of the entire nation. They were mainly around from 10 the humid and sub-humid regions of Qinling to the south of the Huaihe River, Daxing, to Xiaoxing Anling (the eastern part of Inner Mongolia),and to the eastern margin of the Qinghai-Tibet Plateau, which are mainly covered with forested land. On the other hand, the areas where a decrease of NPP caused by climate changes accounted for $47 \%$ of the entire nation were mainly around the eastern part of the Sanjiang Plain, 15 Huang-Huai-Hai Plain, and southern hilly areas, which were mainly covered with farmland.

Table 1 shows an increasing trend of NPP and HR in the same period. With an annual average rate of $0.01 \mathrm{PgC} / \mathrm{y}$ over the 20-year time period, $\mathrm{HR}$ increased by an annual average rate of $0.057 \mathrm{Pg} \mathrm{C}$ per year from 1981 to 1990 , and $0.079 \mathrm{PgC}$ per year from 1991 to 2000 (see Table 1). The correlation coefficients between HR and temperature as well as between HR and precipitation were 0.92 and 0.39 , respectively. These research findings clearly indicate that HR increased significantly due to the increasing temperature and precipitation in most areas of China in the study period from 1990 to 1999. Even though the temperature plays a more critical role than the precipitation, it is believed that the increase in precipitation promoted the growth of vegetation and soil respiration leading to a significant increase of HR.

To draw on further conclusions based on findings spatially, Fig. 7 shows the spatial changes of five parameters in relation to the annual average carbon storage and carbon flux over the study period. The areas where HR was increasing during the study
BGD

7, 5517-5555, 2010

\section{Impact of climate and land use/cover changes on the carbon cycle in China}

Z. Gao et al.

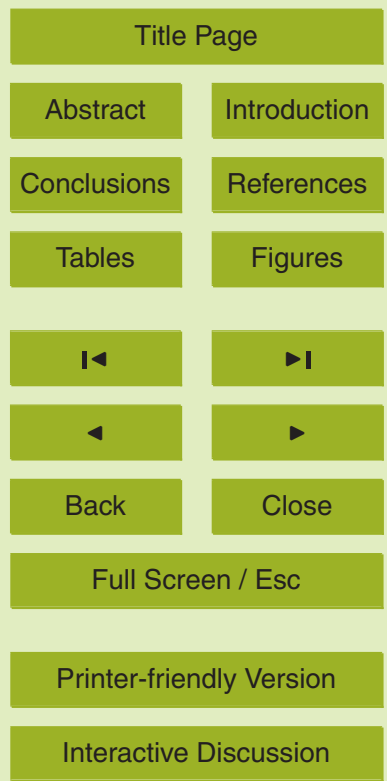


period accounted for $22 \%$ of the entire nation. They were mainly around from the eastern margin of the Qinghai-Tibet Plateau, to eastern part of the Inner Mongolia, to the Tianshan Mountains, and to the oasis of the Tarija Basin region (see Fig. 7c). Besides, the areas where the HR decreased in the same period accounted for $46 \%$ of the entire 5 nation. They were mainly around the three provinces of Northeast China, North China, the Loess Plateau, and the southern area of the Nanling Mountains.

The collective changes in NPP and HR over the study period also led to some fluctuations in NEP, as can be seen in Fig. 7b. In general, NEP experienced a decreasing trend over the study period. Table 1 also confirms that NEP had a positive value from 101981 to 1995 , which implies that the effect of carbon uptake associated with the carbon cycle in China resulted in an increase of $S O C$ and vegetation carbon. The annual SOC and VEGC increased by $0.32 \mathrm{Pg} \mathrm{C}$ and $0.009 \mathrm{PgC}$ on average, respectively. Together with the mild increase in temperature and significant increase in precipitation from 1996 to 2000, the soil respiration also increased more significantly than did NPP. 15 It led to an enhancement of the process of carbon cycling in most areas of China by which the impact of carbon uptake was replaced with carbon release. These changes certainly decreased the accumulation of soil carbon. As a consequence, the SOC declined by $0.098 \mathrm{Pg} \mathrm{C}$, yet the VEGC increased by $0.064 \mathrm{Pg} \mathrm{C}$ from 1996 to 2000 due to the impact of climate changes (see Table 1).

By looking at the areas in Fig. $7 \mathrm{~b}$, it is clear that the areas with an NEP $<0$ were around from the south of the Huaihe River to the Qinling Mountains, which belong to the tropical and subtropical regions, and in the area of the Daxing and Xiaoxing Mountains, which were covered mainly by woodlands. In these areas, there was an effect of carbon release associated with the carbon cycle. The areas in Fig. $7 \mathrm{~b}$ with an NEP greater than 0 was around the three provinces of Northeast China, the Eastern Inner Mongolia, the North China Plain, and the eastern part of Qinghai-Tibet. There was an effect of carbon uptake associated with the carbon cycle. The areas with an NEP $>0$ accounted for $33 \%$ of the entire nation in 1980s; yet the number became $38 \%$ of the entire nation in the 1990s. Our research results clearly show that the areas
BGD

$7,5517-5555,2010$

\section{Impact of climate and land use/cover changes on the carbon cycle in China}

Z. Gao et al.

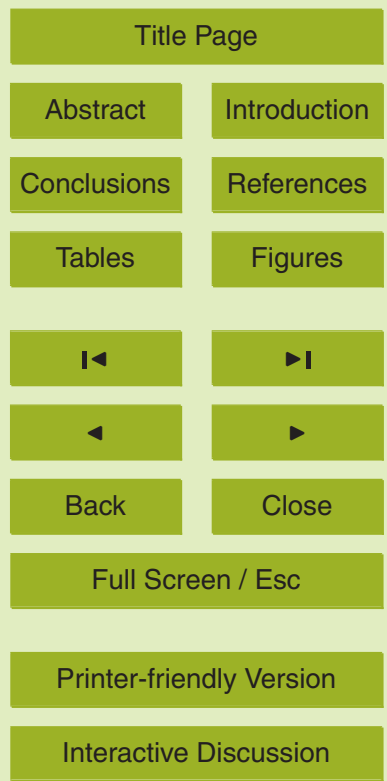


with the positive effect of carbon uptake associated with the carbon cycle expanded. Overall, the carbon cycle in China was dominated by the effect of carbon uptake from 1990 to 1994, followed by the effect of carbon release from 1995 to 2000.

Figure $7 d$ shows that the areas where increased VEGC accounted for $37 \%$ of the

5 entire nation. They were mainly around the Loess Plateau, North China Plain, and the Daxiaoxing Mountains. The areas with decreased VEGC accounted for $31 \%$ of the entire nation. They were around Xinjiang, Inner Mongolia, the North China Plain, and the Sanjiang Plain area. In Fig. 7e the area of increased SOC accounted for $32 \%$ of the entire nation. They were mainly around the south of the Huaihe River, the Qinling 10 Mountains, South China, the Daxing, and Xiaoxing Mountains, and north and south corridor along the Tianshan Mountains. The areas where decreased SOC accounted for $38 \%$ of the entire nation, and they were mainly distributed in the northern provinces and autonomous regions to the north of the Huaihe River (see Fig. 7e).

In summary, with the warmer climate and increased precipitation within the study 15 period in China, the trend toward increases in HR and NPP was obvious. From 1981 to 1995 , the increase in NPP was greater than that of HR, and the ecosystems in China had taken up more carbon in the carbon cycle, leading to the situation that the total carbon storage in China increased by $0.33 \mathrm{PgC}$. From 1996 to 2000, the temperature increased significantly, leading to a marked increase of HR, which was higher than that of NPP (see Fig. 7a). The status of the ecosystems as a whole was shifted from a carbon sink to a carbon source resulting in a total carbon decrease by about 0.034 Pg C in China (Cao et al., 2003, 2004, 2005; Fang et al., 2001, 2003).

\subsection{The impacts of LUCC on carbon storage and carbon flux}

With the linkage between the CEVSA model and the LULC, we were able to numeri-

cally calculate VEGC, SOC, NPP and HR, helping understand the effects of LUCC on carbon storage and carbon flux which may be produced with the bookkeeping model for 1980s and 1990s in China (Liu et al., 2005). Table 2 summarizes the LUCC matrix that was applied to meet this goal. The vertical dimension recorded the LULC in 1990

BGD

$7,5517-5555,2010$

\section{Impact of climate and land use/cover changes on the carbon cycle in China}

Z. Gao et al.

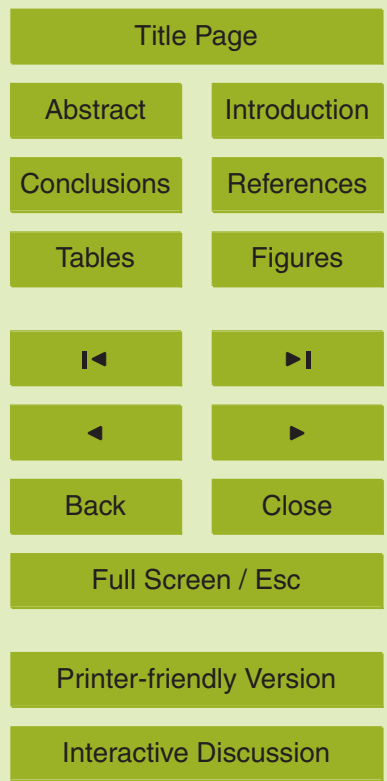


which was used as a benchmark to capture the decadal changes of LUCC in 2000 as listed along the horizontal axis. Within this matrix, LUCC eventually can be calculated at its bottom row.

Overall, the total area of LUCC is $138029 \mathrm{~km}^{2}$ accounting for $1.45 \%$ of the total 5 land area nationally (Liu et al., 2005). This reflects changes of $31651 \mathrm{~km}^{2}$ of cropland $(22.9 \%), 27196 \mathrm{~km}^{2}$ of woodland $(19.7 \%), 56449 \mathrm{~km}^{2}$ of grassland $(40.9 \%), 6215 \mathrm{~km}^{2}$ of water body $(4.5 \%), 161 \mathrm{~km}^{2}$ of constructed land $(0.1 \%)$, and $16357 \mathrm{~km}^{2}$ of unused land (11.9.9\%). The area of the three major land covers including cropland, woodland and grassland in 1990 occupied approximately $83 \%$ of total LUCC, which revealed the 10 fact that a fair amount of woodland and grassland were cultivated as cropland around North and West China, and were occupied as constructed land in the eastern coast of China during that time period.

The densities of VEGC, SOC, NPP and HR were then calculated based on the two LULC datasets from 1990 and 2000. Figure 8 shows the comparison of these val15 ues generated between the CEVSA simulation outputs and values in the literature by Houghton et al. (2003). It can be seen that SOC density had not undergone significant changes. The VEGC density in cropland and woodland were also very close. Yet there were big differences of vegetation densities at grassland and unused land between the CEVSA simulation outputs and those produced by Houghton et al. (2003). Integrating the densities of NPP, HR, VEGC and SOC simulated by the CEVSA model with the differences of land cover in 1990 and 2000 and the land transformation matrix data eventually allowed us to calculate the changes of carbon storage and carbon flux under the influence of LUCC between 1990 and 2000. Since the changed area of constructed land, water body and unused land accounted for $64.4 \%$ of the total cropland changes and the carbon densities of these three types of land cover were very low, the LUCC resulted in a net decrease of NPP, HR, VEGC and SOC by about $0.0135 \mathrm{Pg} \mathrm{C}$, $0.0139 \mathrm{PgC}, 0.008 \mathrm{PgC}$ and $0.215 \mathrm{PgC}$, respectively (see Fig. 8). According to Table 2 , the area of cropland and woodland in the 2000 s accounted for $80 \%$ of total change of grassland in 1990s, and obviously the carbon densities of the cropland and
BGD

$7,5517-5555,2010$

\section{Impact of climate and land use/cover changes on the carbon cycle in China}

Z. Gao et al.

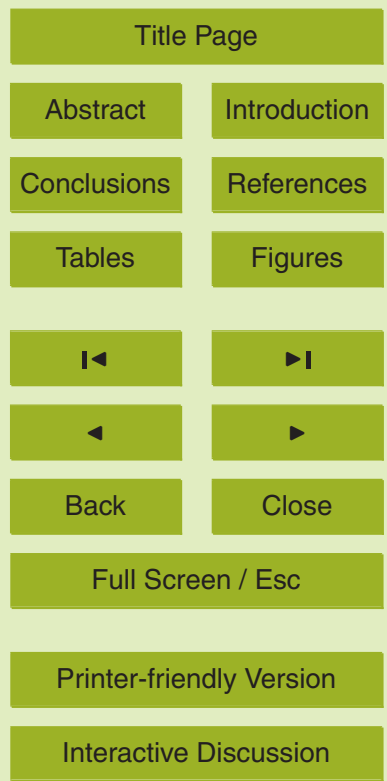


woodland were much higher than that of grassland, causing a net increase of NPP, HR, VEGC and SOC by about $0.0144 \mathrm{Pg} \mathrm{C}, 0.0146 \mathrm{Pg} \mathrm{C}, 0.044 \mathrm{TgC}$ and $0.111 \mathrm{Pg} \mathrm{C}$, respectively (see Fig. 8). On the other hand, $16357 \mathrm{~km}^{2}$ of the unused land was transformed into cropland $\left(6587 \mathrm{~km}^{2}\right)$, woodland $\left(401 \mathrm{~km}^{2}\right)$, grassland $\left(6599 \mathrm{~km}^{2}\right)$, water 5 body $\left(2280 \mathrm{~km}^{2}\right)$ and constructed land $\left(490 \mathrm{~km}^{2}\right)$, resulting in higher carbon densities of the land cover. It caussed a net increase of NPP, HR, VEGC, and SOC by about $0.0048 \mathrm{Pg} \mathrm{C}, 0.0049 \mathrm{Tg}, 0.0097 \mathrm{Pg} \mathrm{C}$ and $0.1 \mathrm{Pg} \mathrm{C}$, respectively (see Fig. 8). Overall, when compared to the LULC over the two decades of interest, the final carbon densities of land cover in 1990s ended up a net decrease of NPP, HR, VEGC and SOC by about $0.0057 \mathrm{Pg} \mathrm{C}, 0.0055 \mathrm{Pg}, 0.08 \mathrm{Pg} \mathrm{C}$ and $0.137 \mathrm{Pg} \mathrm{C}$, respectively (see Fig. 8).

With many changes of the pattern of LULC, Fig. 9 finally summarizes the comparative values of NPP, HR, VEGC and SOC as a whole. It shows that the LUCC from 1990 to 2000 reflected the changed areas accounting for $1.45 \%$ of total national wide. It rendered a net increase of NPP and HR by $0.0021 \mathrm{Pg} \mathrm{C}$ and $0.0023 \mathrm{Pg} \mathrm{C}$, respectively, on one hand, and a net decrease of VEGC, SOC, and total carbon storage by $0.03 \mathrm{PgC}$, $0.097 \mathrm{Pg} \mathrm{C}$, and $0.126 \mathrm{Pg} \mathrm{C}$, respectively, on the other hand. Table 3 lists all the key values in this statistical analysis.

The area which experienced the increased NPP caused by LUCC is mainly located in Northeast China, Inner Mongolia and the north-south of Tianshan Mountains due to the increase of cropland. Hence, the areas where NEP increased caused by LUCC were also around the same region (see Fig. 10). In summary, NPP was $0.051 \mathrm{Pg} \mathrm{C} / \mathrm{y}$ of 2000 and $0.0487 \mathrm{PgC}$ of 1990 in areas where LUCC occurred and the LUCC eventually led to an increase of NPP by about $0.002 \mathrm{Pg} C$. The areas where an increase of HR caused by LUCC occurred were mainly around Southern China, as opposed to Northern China where HR decreased. Changes in land use led to a net increase of HR by about $0.0023 \mathrm{Pg}$ C.

According to Fig. 9, the net increases of NPP and HR resulted in the changes of the NEP because the LUCC eventually led to net increases of NPP that were greater than net increases of HR (see Table 3). As a consequence, the LUCC behaved as

BGD

$7,5517-5555,2010$

\section{Impact of climate and land use/cover changes on the carbon cycle in China}

Z. Gao et al.

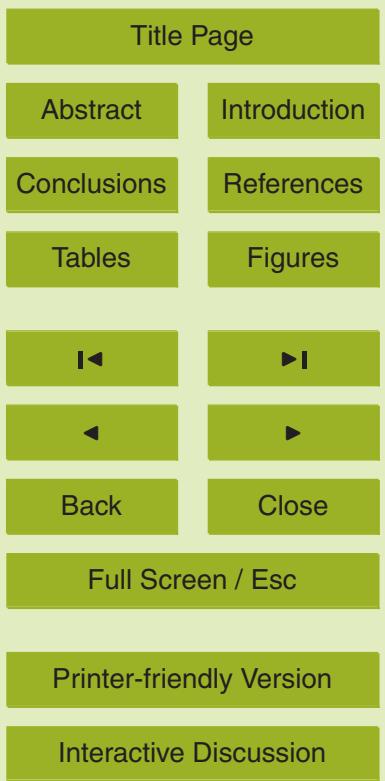


a carbon "sink" in China's ecosystem during that two decades. This is mainly because fast economic development resulted in an increase of farmland, constructed land and a decrease of woodland and grassland within the time period of 1991-2000. Although the trend of increasing NPP was obvious due to the increase in farmland, the decrease 5 of woodland and grassland even outweigh it, resulting in a net decrease of VEGC and SOC. These changes led to the net decrease of $0.03 \mathrm{Pg} \mathrm{C}$ of VEGC and $0.097 \mathrm{Pg} \mathrm{C}$ of sOC (see Table 3).

\section{Final remarks}

\subsection{Uncertainties in carbon cycle analysis}

10 The impacts of LUCC on carbon flux and carbon storage are deemed very complex (Houghton et al., 1999, 2000; Houghton and Hackler, 2003; Houghton, 2003a,b). Changes in climate and LULC intermittently affect the ecological system and hydrological cycle. In the early stages, large-scale and continuous monitoring data of the LULC did not exist (Liu et al., 2005a,b), making our study count on two snapshots of 15 LULC in 1990 and 2000 as representative LULC patterns for assessment. However, even the supervised classification during the study years (1990 and 2000) may add some more uncertainties. Besides, the CEVSA cannot model all of the changes of materials and energy in ecosystem caused by the LUCC. Thus, the integration of the CEVSA with LUCC data derived from remote sensing in the context of bookkeeping model add yet more uncertainties. This results in an expanded array of uncertainty in the quantitative assessment of the impacts of climate change and LUCC on carbon flux and carbon storage. They can be summarized as follows:

1. The prediction accuracy of the LUCC developed by the use of Landsat TM scenes with a spatial resolution of $30 \times 30 \mathrm{~m}$ (Liu et al., 2005) may be improved by the image matching, image quality and the experiences of interpretation.
BGD

$7,5517-5555,2010$

\section{Impact of climate and land use/cover changes on the carbon cycle in China}

Z. Gao et al.

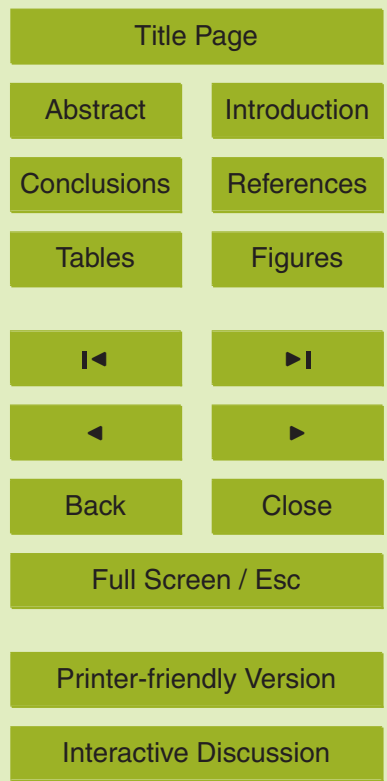


2. Because the CEVSA does not simulate changes of soil physical structures and model the ecosystem process, it results in large impacts on SOC estimation. This led to a certain degree of uncertainty on the calculation of SOC pool (Cao et al., 1998a,b, 2003; Woodward et al., 1995).

3. The effects of the changes in the hydrological cycle caused by the LUCC on the carbon cycle are not interconnected with each other in the CEVSA model. This may directly affect the accurate estimates of storage capacity of SOC, and thus the rate of carbon emission or absorption (Cao et al.; 1998a, 2003; Gao et al., 2005).

4. All of these concerns would accumulate in the context of the integrative framework involving a large number of parameters and default variables in our simulation. Whereas some parameters were obtained from field survey or estimated by experience, ground-based stations of carbon flux are not widely applied (Gao et al., 2005).

15 Overall, the CEVSA model cannot investigate the differences of SOC pools contiguously and the hydrological cycle effected by LUCC continuously over the 1980s and 1990s. The complexity and the time lag of impacts of LUCC on the ecological environment, therefore account for the major portion of the uncertainties in this study.

\subsection{Comparison with other estimates}

20 The total NPP (i.e., 3.21 Pg/y) simulated by the CEVSA model in this study is very close to that estimated by the TEM model (i.e., 3.65 Pg C/y) (Xiao et al., 1998) the, CASA model (i.e., 2.746 Pg/y), and the GLOPEM model (2.973 Pg/y) (Gao et al., 2008). The total SOC (i.e., 75.27 Pg C/y) simulated by the CEVSA model is lower than that estimated by Wang et al. (2001) (i.e., 92.4 Pg C/y) and Wu et al. (2003a,b) (77.4 Pg C/y), both of which were based on the second national soil survey of China. The VEGC (i.e., $11.58 \mathrm{Pg}$ ) calculated in our study is also close to that estimated by the bookkeeping

BGD

$7,5517-5555,2010$

\section{Impact of climate and land use/cover changes on the carbon cycle in China}

Z. Gao et al.

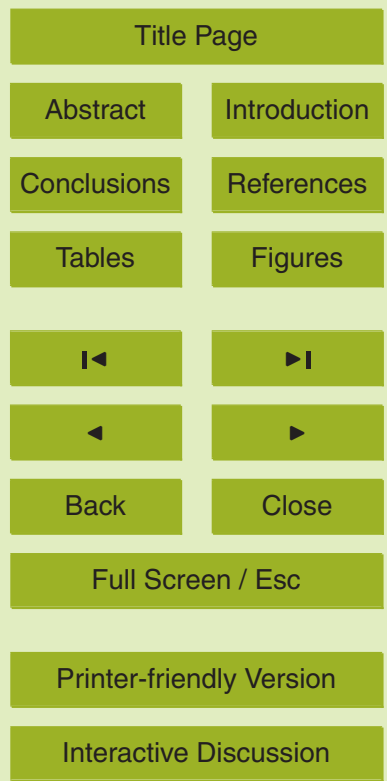


model (i.e., 11.6 Pg) (Houghton et al., 2003b). With this knowledge, the carbon flux estimated in this study was $0.017 \mathrm{Pg} / \mathrm{y}$ which makes the Chinese ecosystem an overall carbon sink . Fang et al. (2001) reported an average uptake $(0.021 \mathrm{Pg} \mathrm{C} / \mathrm{y})$ for the years from 1980 to 1998 . Their estimates are based on changes in forest biomass 5 only. Houghton (2003a) estimated the carbon flux of China for the last several years of the 1990s ranging between 0.02 and $0.05 \mathrm{Pg} \mathrm{C} / \mathrm{y}$, which also indicated a carbon sink. These recent carbon sinks are similar to the estimates in some literature (Fang et al., 2001; Wang et al., 2001; Houghton et al., 2003b; Ge et al., 2008). So our carbon flux (this study) was close to that of Fang et al. (2001) and Houghton et al. (2003b).

10 The carbon cycle in China as simulated by the CEVSA between 1981 and 2000 in this study supports the observation that the Chinese terrestrial ecosystem was an overall carbon sink from 1981 and 1996 since the NEP was positive. But it was a carbon source between 1996 and 2000 since the NEP was negative (Houghton et al., 2003b; Fang et al., 2001). In the period of 1990-2000, based on the difference of carbon

densities of land cover simulated by the CEVSA model associated with LUCC data, the carbon cycle changes were calculated with the aid of the bookkeeping model in response to an area only accounting for $1.45 \%$ of total national area where land use change occurred. We concluded that the terrestrial ecosystem in these areas where land use changes had occurred was a carbon source since the NEP was negative. Overall, the average NPP was $3.21 \mathrm{Pg} / \mathrm{y}$ and the average HR was $3.15 \mathrm{Pg} / \mathrm{y}$. Consequently, the positive NEP (NPP-HR) supports the claim that the terrestrial ecosystem of China as a whole appeared was a carbon sink between 1981 and 2000. This judgment is consistent with several other studies (Fang et al., 2001, 2003; Piao et al., 2005; Zhao and Zhou, 2005; Houghton et al., 2003b; Ge et al., 2008, Wang et al., 2003; Wu et al., 2003a,b; Xiao, et al., 1998; Li et al., 2005).

It is known that the artificial afforestation has been carried out extensively over large areas in China since 1949 (Fang et al., 1998, 2001; Feng et al., 1999; Li et al., 2004; Pan et al., 2004). In the last 20 years, the Chinese Government has successively launched six afforestation projects. They include the Natural Forest Protection Program
BGD

$7,5517-5555,2010$

\section{Impact of climate and land use/cover changes on the carbon cycle in China}

Z. Gao et al.

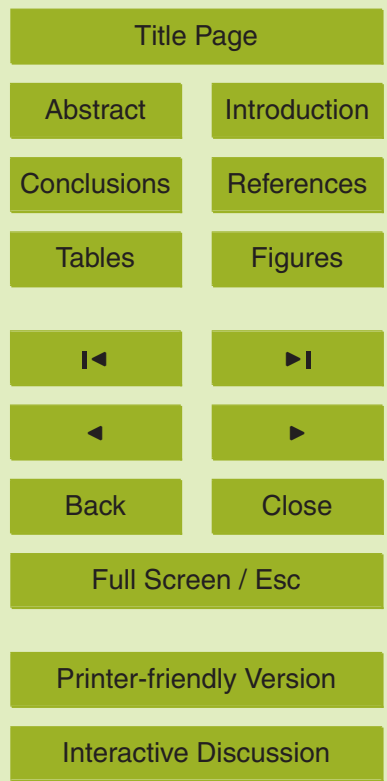


(1998-2008), the Returning Farmland to Forest Engineering Program initiated in 1997, the Protection Forest program of "Three North" and the Yangtze River system and other key areas, the Sandstorm Source Control Project of Beijing and Tianjin (2003-2007), the Wild Animal and Natural Plant Protection and Nature Reserve Project (2001-2010),

5 and the Fast Growing Timber Forest Bases Project in key areas initiated in 2002. Due to the impacts of these six afforestation projects in promoting increased forest coverage, China's forest cover increased from $8.6 \%$ of 1949 to $18.21 \%$ of 2007 (Development Gateway, 2010). This might appear contradictory to the findings we had in the LUCC since there is a net decrease of woodland area of $10895 \mathrm{~km}^{2}$ when comparing the 10 LULC in 2000 to that in 1990. This implies that if the LUCC occurred before 1990 or after 2000, it would not be reflected in the LUCC information and hence the CEVSA modeling process. This judgment can be confirmed by the fact that five out of the six major afforestation projects were initiated and/or continued in 1997 and thereafter.

\section{Conclusions}

15 This study applied the CEVSA model driven by both high resolution LULC and climate data to analyze the impacts of climate changes and LUCC on carbon flux and carbon storage in China from 1980 to 2000. Being the first effort of large-scale assessment of it kind based on high resolution LULC data, modeling outputs showed that the NPP and $\mathrm{HR}$ were increased due to climate changes with an increase of average annual temperature of $0.055^{\circ} \mathrm{C}$ and precipitation with an increase of the annual precipitation rate of $0.65 \mathrm{~mm} / \mathrm{y}$ from 1981 to 2000 in China. Based on the simulated outputs of the CEVSA model, the average NPP of China is $3.21 \mathrm{Pg} \mathrm{C} / \mathrm{y}$, the average VEGC is $11.58 \mathrm{Pg} / \mathrm{y}$ and the average SOC is 75.27 Pg C/y. Between 1981 and 1995, the increase of NPP was larger than that of HR, resulting in a positive value of NEP. The positive NEP led to effects of carbon uptake in the carbon cycles so that the total carbon of VEGC and SOC increased by 0.33 Pg C in the ecosystems of China. Between 1996 and 2000, the NEP value was negative due to the increases in HR that were larger than that of NPP.

BGD

7, 5517-5555, 2010

\section{Impact of climate and land use/cover changes on the carbon cycle in China}

Z. Gao et al.

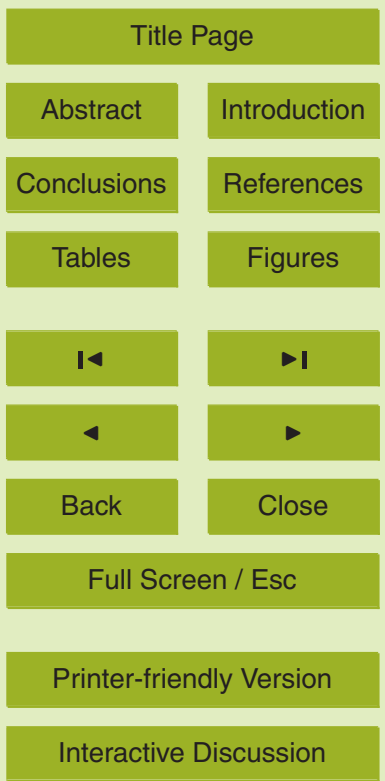


This negative NEP led to a decrease of carbon storage by $0.034 \mathrm{Pg} \mathrm{C}$. Overall, in the two decades, climate changes led to an increase in the total SOC by $0.223 \mathrm{PgC}$ and VEGC by $0.073 \mathrm{PgC}$ in China, resulting in a total increase of carbon of $0.296 \mathrm{Pg} \mathrm{C}$.

When taking the multitemporal LULC into account, the LUCC was fully recognized 5 by using remote sensing technology. Overall, the LUCC accounted for $1.45 \%$ of the total national land area. With a bookkeeping model, we integrated the Chinese LUCC dataset with the carbon densities of the land cover calculated by the CEVSA model over $1980 \mathrm{~s}$ and 1990s. It can be concluded that the VEGC was $0.161 \mathrm{Pg} / \mathrm{y}$ in the $1980 \mathrm{~s}$ and $0.131 \mathrm{Pg} / \mathrm{y}$ in the $1990 \mathrm{~s}$; the SOC was $1.165 \mathrm{Pg} / \mathrm{y}$ in the $1980 \mathrm{~s}$ and $1.068 \mathrm{Pg} / \mathrm{y}$ in the 10 1990s. The VEGC was reduced by $0.0295 \mathrm{Pg}$ and the SOC by $0.0968 \mathrm{Pg}$ due to the LUCC between 1990 and 2000; therefore, the total carbon was reduced by $0.126 \mathrm{Pg} \mathrm{C}$. This led to the final conclusion that the total carbon was increased by $0.296 \mathrm{PgC}$ due to climate change and was decreased by $0.126 \mathrm{PgC}$ due to the LUCC. As a result, the total carbon increased was $0.17 \mathrm{PgC}$. The carbon flux of the ecosystem in China was $15 \quad 0.017 \mathrm{Pg} \mathrm{C} / \mathrm{y}$ on average during the study period.

It can be concluded that the changes of carbon flux and carbon storage caused by climate change were absolutely larger than that caused by the LUCC from 1981 to 2000 in China. This can be evidenced by that both NPP and HR increased under the influence of climate change due to higher temperatures and higher annual precipitation.

20 The increase of NPP was larger than that of HR so that the ecosystem in China leaned toward taking more carbon within the carbon cycle for at least $80 \%$ of total study time period. This led to upward trends toward the increase of VEGC and SOC. During the same time period, although China's terrestrial ecosystem where LUCC occurred was a carbon source, the rest of the regions, accounting for $98.55 \%$ of the total area, was 25 actually a carbon sink resulting in a net increase of total carbon (i.e., VEGC and SOC). This trend is in agreement with some other research though.

Acknowledgements. This work was collectively supported by National 973 Key Project of China (The assessment, assimilation, fusion and application of global change data), creative group project of national key laboratory (1088RA400S) and USDA CSREES (2006-34263-16926).
BGD

$7,5517-5555,2010$

\section{Impact of climate and land use/cover changes on the carbon cycle in China}

Z. Gao et al.

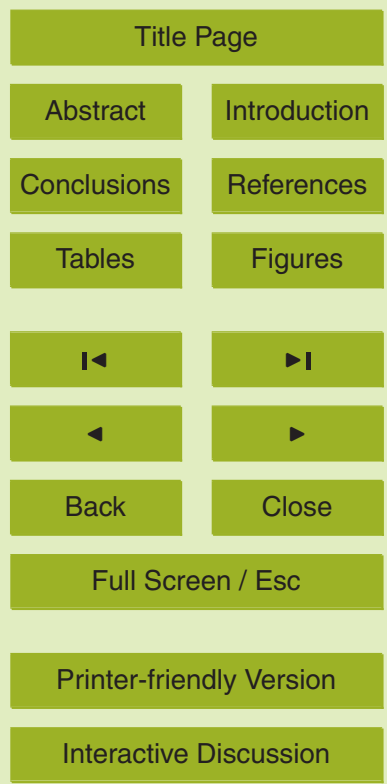




\section{References}

Braswell, B. H., Schimel, D. S., Linder, E., and Moore, B.: The response of global terrestrial ecosystems to interannual temperature variability, Science, 278, 870-873, 1997.

Bousquet, P., Peylin, P., Ciais, P., Le Quéré, C., Friedlingstein, P., and Tans, P. P.: Regional changes in carbon dioxide fluxes of land and oceans since 1980, Science, 290, 1342-1346, 2000.

Cao, M. K. and Woodward, F. I.: Dynamic responses of terrestrial ecosystem carbon cycling to global climate change, Nature, 393, 249-252, 1998a.

Cao, M. K. and Woodward, F. I.: Net primary and ecosystem production and carbon stocks of terrestrial ecosystems and their responses to climate change, Glob. Change Biol., 4(3), 185-198, 1998b.

Cao, M. K., Zhang, Q., and Shugart, H. H.: African ecosystem carbon cycle and climate change, Clim. Res., 17, 183-193, 2001.

Cao, M. K., Prince, S. D., and Shugart, H. H.: Increasing terrestrial carbon uptake from the 1980 s to the 1990 s with changes in climate and atmospheric $\mathrm{CO}_{2}$, Global Biogeochem. Cy., 16, 1069, doi:10.1029/2001 GB001553, 2002.

Cao, M. K., Price, S., Li, K. R., Tao, B., Small, J., and Shao, X.: Response of terrestrial carbon uptake to climate interannual variability in China, Glob. Change Biol., 9, 536-546, 2003.

Cao, M. K., Prince, S. D., Small, J., and Goetz, S.: Satellite remotely sensed interannual variability in terrestrial net primary productivity from 1980 to 2000, Ecosystems, 7, 233-242, 2004.

Cao, M. K., Prince, D. S., Tao, B., Small, J., and Li, K. R.: Regional pattern and interannual variations in global terrestrial carbon uptake in response to changes in climate and atmospheric $\mathrm{CO}_{2}$, Tellus, 57B, 210-217, 2005.

25 Caspersen, J. P., Pacala, S. W., Jenkins, J. C., Hurtt, G. C., Moorcroft, P. R., and Birdsey, R. A.: Contributions of land-use history to carbon accumulation in US forests, Science, 290, 1148$1151,2000$.

DeFries, R. S., Field, C. B., and Fung, I.: Combining satellite data and biogeochemical models to estimate global effects of human-induced land cover change on carbon emissions and primary productivity, Global Biogeochem. Cy., 13(3), 803-815, 1999.

Development Gateway - China and Southeast Asia Free Trade Zone: http://cn.chinagate.cn/ resource/2007-12/19/content_9400552.htm, last access: 20 October 2009. 2010.
BGD

7, 5517-5555, 2010

\section{Impact of climate and land use/cover changes on the carbon cycle in China}

Z. Gao et al.

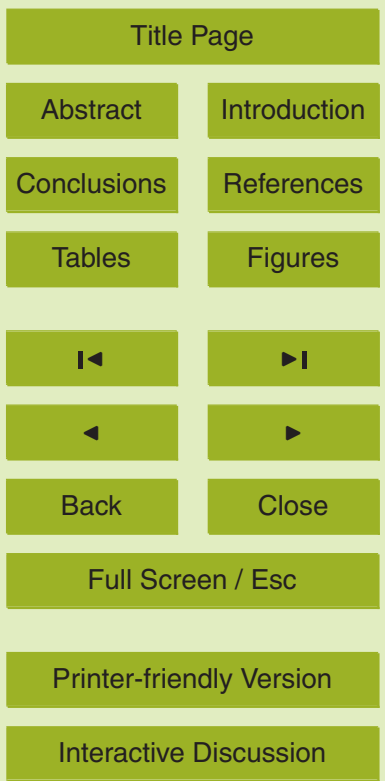


Fang, J. Y., Liu, G. H., and Xu, S. L.: Soil carbon pool in China and its global significance, J. Environ. Sci., 8, 249-254, 1996.

Fang, J. Y., Wang, G. G., Liu, H. G., and Xu, S. L.: Forest biomass of China: an estimate based on the biomass-volume relationship, Ecol. Appl., 8, 1084-1091, 1998.

5 Fang, J. Y., Chen, A. P., Peng, C. H., Zhao, S. Q., and Ci, L. J.: Changes in forest biomass carbon storage in China between 1949 and 1998, Science, 292, 2320-2322, 2001.

Fang, J. Y. and Chen, A. P.: Dynamic forest biomass carbon pools in China and their significance, Acta Bot. Sin., 43, 967-973, 2001.

Fang, J. Y., Piao, S. L., Field, C., Pan, Y., Guo, Q., Zhou, L., Peng, C. H., and Tao, S.: Increasing net primary production in China from 1982 to 1999, Front. Ecol. Environ., 1, 293-297, 2003.

Feddema, J. J., Oleson, K. W., Bonan, G. B., Mearns, L. O., Buja, L. E., Meehl, G. A., and Washington, W. M.: The importance of land-cover change in simulating future climates, Science, 310, 1674-1678, 2005.

Gao, Z. Q., Liu, J. Y., Cao, M. K., Li, K. R., and Tao, B.: Impacts of land-use and climate 15 changes on ecosystem productivity and carbon cycle in the cropping-grazing transitional zone in China, Sci. China, 48, 1479-1491, 2005.

Gao, Z. Q. and Liu, J. Y.: Simulation study of China net primary production, Chinese Sci. Bull., 53(3), 434-443, 2008.

Gao, Q., Yu, M., and Yang, X. S.: An analysis of sensitivity of terrestrial ecosystem in China to climate change using spatial simulation, Clim. Change, 47, 373-400, 2000.

Ge, Q. S., Dai, J. H., He, F. N., Pan, Y., and Wang, M. M.: Land use changes and their relations with carbon cycles over the past 300 a in China, Sci. China, 51(6), 871-884, 2008.

$\mathrm{Gu}, \mathrm{F}$. X. and Cao, M. K.: A comparison between simulated and measured $\mathrm{CO}_{2}$ and water flux in a sub-tropical coniferous forest, Sci. China, 49 (Suppll), 241-251, 2006.

Guo, L. B. and Gifford, R. M.: Soil carbon stocks and land use change: a meta analysis, Glob. Change Biol., 8(2), 345-360, 2002.

Houghton, R. A., Hobbie, J. E., Melillo, J. M., Moore, B., Peterson, B. J.: Changes in the carbon content of terrestrial biota and soils between 1860 and 1980 - a net release of $\mathrm{CO}_{2}$ to the atmosphere, Ecol. Monogr., 53, 235-262, 1983.

30 Houghton, R. A., Boone, R. D., and Fruci, J. R.: The flux of carbon from terrestrial ecosystems to the atmosphere in 1980 due to changes in land use: geographic distribution of the global flux, Tellus, 39B, 122-139, 1987.

Houghton, R. A.: Tropical deforestation and atmospheric carbon dioxide, Clim. Change, 19(1-

BGD

$7,5517-5555,2010$

\section{Impact of climate and land use/cover changes on the carbon cycle in China}

Z. Gao et al.

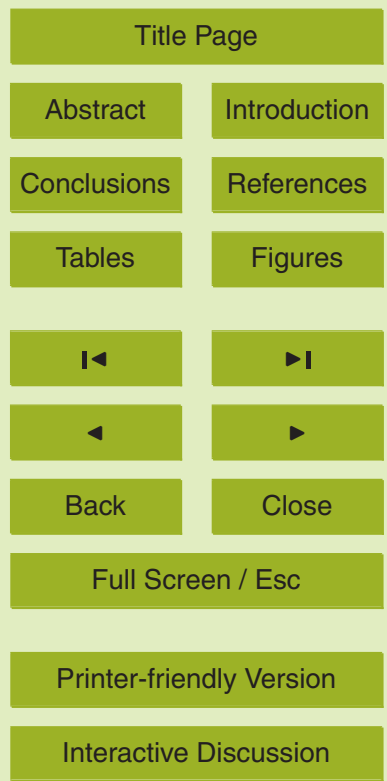


2), 99-118, 1991.

Houghton, R. A. and Hackler, J. L.: Emissions of carbon from forestry and land-use change in tropical Asia, Glob. Change Biol., 5, 481-492, 1999.

Houghton, R. A.: The annual net flux of carbon to the atmosphere from changes in land use 1850-1990, Tellus, 51B, 298-313, 1999.

Houghton, R. A., Hackler, J. L., and Lawrence, K. T.: The US carbon budget: contributions from land-use change, Science, 285, 574-578, 1999.

Houghton, R. A. and Hackler, J. L.: Changes in terrestrial carbon storage in the US. 1: The roles of agriculture and forestry, Global Ecol. Biogeogr., 9, 125-144, 2000.

10 Houghton, R. A.: Why are estimates of the terrestrial carbon balance so different, Global Change Biol., 9, 500-509, 2003a.

Houghton, R. A.: Revised estimates of the annual net flux of carbon to the atmosphere from changes in land use and land management 1850-2000, Tellus, 55B, 378-390, 2003b.

Houghton, R. A. and Hackler, J. L.: Sources and sinks of carbon from land-use change in China, Global Biogeoch. Cy., 17(2), 1034, 2003.

Houghton, R. A.: Aboveground forest biomass and the global carbon balance, Global Change Biol., 11, 945-958, 2005.

Jiang, H., Apps, M. J., Zhang, Y. L., Peng, C. H., and Woodard, P.: Modeling the spatial pattern of net primary productivity in Chinese forests, Ecol. Model, 122, 225-238, 1999.

John, P. C., Stephen, W. P., Jennifer, C. J., George, C. H., Paul, R. M., and Richard, A. B.: Contributions of land-use history to carbon accumulation in US forests, Science, 290, 11481151, 2000.

Klein Goldewijk, K.: Estimating global land use change over the past 300 years: the HYDE database, Global Biogeochem. Cy., 15, 417-433, 2001.

Klein Goldewijk, K. and Ramankutty, N.: Land cover change over the last three centuries due to human activities: the availability of new global data sets, Geojournal, 61, 335-344, 2004.

Li, K. R., Wang, S. Q., and Cao, M. K.: Carbon storage in China's vegetation and soils, Sci. China, 33(2), 72-80, 2003.

Li, K. R., Wang, S. Q., and Cao, M. K.: Vegetation and soil carbon storage in China, Sci. China, 47, 49-57, 2004.

Liu, J. Y., Tian, H. Q., Liu, M. L., Zhuang, D. F., and Melillo, J. M.: China's changing landscape during the 1990s: large-scale land transformations estimated with satellite data, Geophys. Res. Lett., 32, L02405, doi:10.1029/2004GL021649, 2005a.

\section{BGD}

$7,5517-5555,2010$

\section{Impact of climate and land use/cover changes on the carbon cycle in China}

Z. Gao et al.

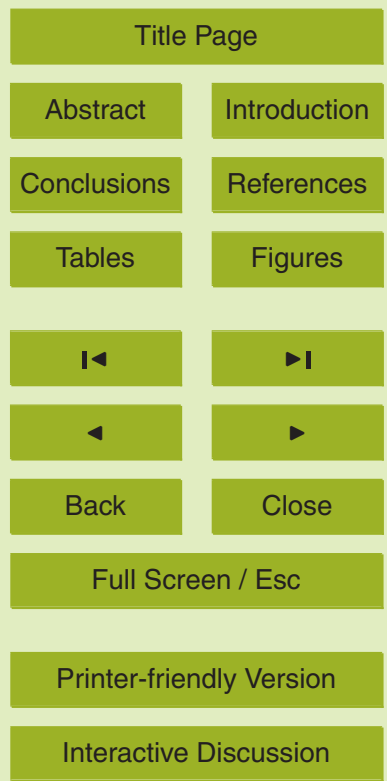


Liu, J. Y., Liu, M. L., Tian, H. Q., Zhuang, D. F., Zhang, Z. X., Zhang, W., Tang, X. M., and Deng, X. Z.: Spatial and temporal patterns of China's cropland during 1990-2000: an analysis based on Landsat TM data, Remote Sens. Environ., 98, 442-456, 2005b.

McGuire, A. D., Sitch, S., Clein, J. S., et al.: Carbon balance of the terrestrial biosphere in the 5 twentieth century: analyses of $\mathrm{CO}_{2}$, climate and land use effects with four process-based ecosystem models, Global Biogeochem. Cy., 15(1), 183-206, 2001.

Melillo, J. M., McGuire, A. D., Kicklighter, D. W., Moore III, B., Vorosmarty, C. J., and Schloss, A. L.: Global climate change and terrestrial net primary production, Nature, 363, 234-240, 1993.

$10 \mathrm{Ni}, \mathrm{J} .:$ Net primary productivity in forests of China: scaling-up of national inventory data and comparison with model predictions, Forest Ecol. Manag., 176, 485-495, 2003.

$\mathrm{Ni}$, J., Zhang, X. S., and Scurlock, J. M. O.: Synthesis and analysis of biomass and net primary productivity in Chinese forests, Ann. For. Sci., 58, 351-384, 2001.

Pacala, S. W., Hurtt, G. C., Baker, D., Peylin, P., Houghton, R. A., et al.: Consistent land- and atmosphere-based US carbon sink estimates, Science, 292, 2316-2320, 2001.

Pan, Y. D., Luo, T. X., Birdsey, R., Hom, J., and Melillo, J. M.: New estimate of carbon storage and sequestration in China's forests: effects of age-class and method on inventory-based carbon estimation, Clim. Change, 67, 211-236, 2004.

Peng, C. H., Zhou, X. L., Zhao, S. Q., Wang, X. P., Zhu, B., Piao, S. L., and Fang, J. Y.: 20 Quantifying the response of forest carbon balance to future climate change in Northeastern China: model validation and prediction, Global Planet. Change, 66, 179-194, 2009.

Peng, C. H. and Apps, M. J.: Contribution of China to the global carbon cycle since Last Glacial Maximum: reconstruction from paleovegetation maps and an empirical biosphere model, Tellus, 49B, 393-408, 1997.

Piao, S. L., Fang, J. Y., and Zhou, L. M.: Interannual variations of monthly and seasonal normalized difference vegetation index (NDVI) in China from1982 to 1999, J. Geophys. Res., 108(D14), 4401, doi:10.1029/2002JD002848, 2003.

Piao, S. L., Fang, J. Y., Zhou, L. M., Zhu, B., Tan, K., and Tao, S.: Changes in vegetation net primary productivity from 1982 to 1999 in China, Global Biogeochem. Cy., 19, GB2027, doi:10.1029/2004GB002274, 2005.

Phillips, O. L., Malhi, Y., Higuchi, N., Laurance, W. F., Nunez, P. V., Vasquez, R. M., Laurance, S. G., Ferreira, L. V., Stern, M., Brown, S., and Grace, J.: Changes in the carbon balance of tropical forests: evidence from long-term plots, Science, 282, 439-442, 1998.

BGD

$7,5517-5555,2010$

\section{Impact of climate and land use/cover changes on the carbon cycle in China}

Z. Gao et al.

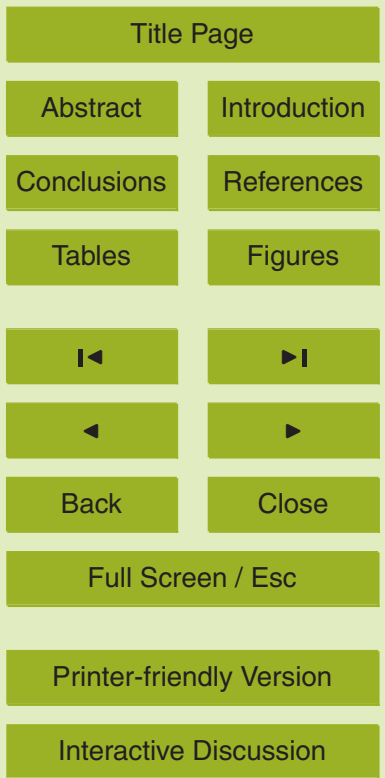


Ramankutty, N. and Foley, J. A.: Estimating historical changes in global land cover: croplands from 1700 to 1992, Global Biogeochem. Cy., 13, 997-1027, 1999.

Ramankutty, N. and Foley, J. A.: Characterizing patterns of global land use: an analysis of global croplands data, Global Biogeochem. Cy., 12(4), 667-685, 1998.

5 Schimel, D. S., Mellio, J., Tian, H. Q., McGuire, A. D., Kicklighter, D., Kittel, T., Rosenbloom, N., Running, S., Thornton, P., Ojima, D., Parton, W., Kelly, R., Sykes, M., Neilson, R., and Rizzo, B.: Contribution of increasing $\mathrm{CO}_{2}$ and climate to carbon storage by ecosystems in the US, Science, 287, 2004-2006, 2000.

Schimel, D. S., House, J. I., Hibbard, K. A., Bousquet, P., Ciais, P., Peylin, P., Braswell, B. H., Apps, M. J., et al.: Recent patterns and mechanisms of carbon exchange by terrestrial ecosystems, Nature, 414, 169-172, 2001.

Sha, W. Y.: Climate changes and impacts to natural regional in China from 1980 to 2000, China Sci., 324(3), 317-326, 2002.

Stephen, D. P. and Samuel, N. G.: Global primary production: a remote sensing approach, 15 J. Biogeogr., 22(2), 815-835, 1995.

Strassmann, K. M., Joos, F., and Fischer, G.: Simulating effects of land use changes on carbon fluxes: past contributions to atmospheric $\mathrm{CO}_{2}$ increases and future commitments due to losses of terrestrial sink capacity, Tellus, 60B, 583-603, 2008.

Vleeshouwers, L. M. and Verhagen, A.: Carbon emission and sequestration by agricultural land use: a model study for Europe, Glob. Change Biol., 8(2),519-530, 2002.

Wang, S. Q., Tian, H. Q., Liu, J. Y., and Pan, S.: Pattern and change of soil organic storage in China: 1960s-1980s, Tellus, 55B, 416-427, 2003.

Wu, H. B., Guo, Z. T., and Peng, C. H.: Land use induced changes of organic carbon storage in soils of China, Glob. Change Biol., 9, 305-315, 2003a.

Wu, H. B., Guo, Z. T., and Peng, C. H.: Distribution and storage of soil organic carbon in China, Global Biogeochem. Cy., 17(2), 179-194, 2003b.

Woodward, F. I., Smith, T. M., and Emanuel, W. R.: A global land primary productivity and phytogeography model, Global Biogeochem. Cy., 9(1), 471-490, 1995.

Xiao, X. M., Melillo, J., Kicklighter, D. W., Pan, Y., McGuire, A. D., and Helfrich, J.: Net primary production of terrestrial ecosystem in China and its equilibrium responses to changes in climate and atmospheric $\mathrm{CO}_{2}$ concentration, Acta Phytoecol. Sin., 23(2), 651-677, 1998.

Zhao, M. and Zhou, G. S.: Estimation of biomass and net primary productivity of major planted forests in China based on forest inventory data, Forest Ecol. Manag., 207, 295-313, 2005.

\section{BGD}

$7,5517-5555,2010$

\section{Impact of climate and land use/cover changes on the carbon cycle in China}

Z. Gao et al.

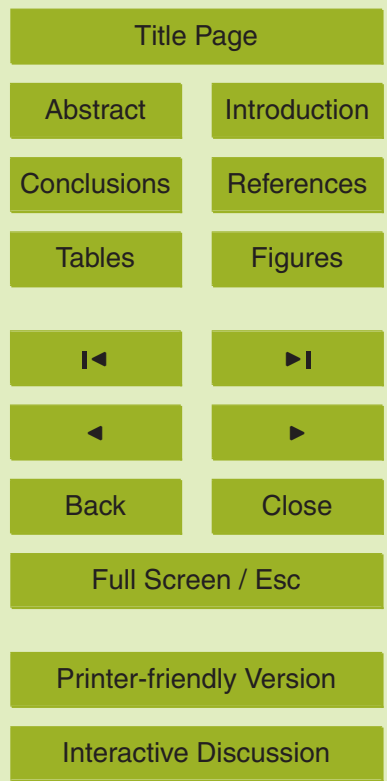




\section{BGD}

$7,5517-5555,2010$

\section{Impact of climate and land use/cover changes on the carbon cycle in China}

Z. Gao et al.

Table 1. The averaged changes of all parameters in relation to carbon cycle over four subperiods (unit: $\mathrm{Pg}$ C).

\begin{tabular}{lcccccccc}
\hline Period & TEMP & PRE & NPP & HR & NEP & SOC & VEGC & Total C \\
\hline $1981-1985$ & 6.09 & 630 & 3.134 & 3.080 & 0.054 & 75.090 & 11.574 & 86.664 \\
$1986-1990$ & 6.51 & 611 & 3.138 & 3.137 & 0.001 & 75.285 & 11.518 & 86.803 \\
$1991-1995$ & 6.57 & 617 & 3.186 & 3.158 & 0.028 & 75.411 & 11.583 & 86.994 \\
$1996-2000$ & 6.98 & 634 & 3.200 & 3.237 & -0.037 & 75.313 & 11.647 & 86.960
\end{tabular}

Note: NPP - net primary production, HR - heterotrophic respiration, NEP - net ecosystem productivity, VEGC vegetation carbon, SOC - soil carbon, TEMP - temperature, PREC - precipitation

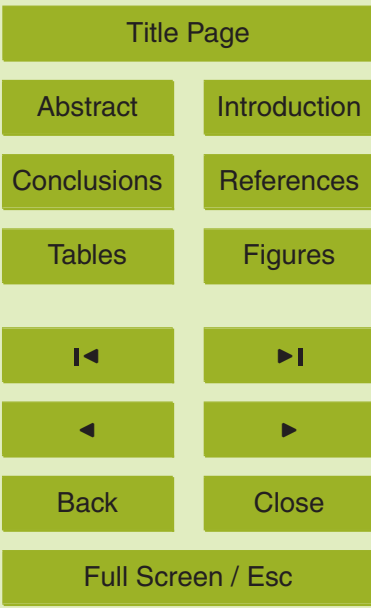

Printer-friendly Version

Interactive Discussion 
BGD

7, 5517-5555, 2010

\section{Impact of climate and land use/cover \\ changes on the carbon cycle in China}

Z. Gao et al.

Table 2. The LUCC matrix at the national scale during 1990-2000 (Unit: km²) (Liu et al., 2005).

\begin{tabular}{|c|c|c|c|c|c|c|c|}
\hline $\begin{array}{l}\text { To } 2000 \\
\text { From } 1990\end{array}$ & Cropland & Woodland & Grassland & Water body & $\begin{array}{l}\text { Constructed } \\
\text { land }\end{array}$ & Unused land & Total (1990) \\
\hline Cropland & & 5159 & 6417 & 3643 & 15090 & 1342 & 31651 \\
\hline Woodland & 17468 & & 8112 & 402 & 930 & 284 & 27196 \\
\hline Grassland & 34568 & 10470 & & 1504 & 766 & 9141 & 56449 \\
\hline Water body & 2858 & 254 & 916 & & 398 & 1789 & 6215 \\
\hline Constructed land & 86 & 20 & 36 & 19 & & 0 & 161 \\
\hline Unused land & 6587 & 401 & 6599 & 2280 & 490 & & 16357 \\
\hline Total (2000) & 61567 & 16304 & 22080 & 7848 & 17674 & 12556 & 138029 \\
\hline Change & 29916 & -10892 & -34369 & 1633 & 17513 & -3801 & \\
\hline
\end{tabular}

Title Page

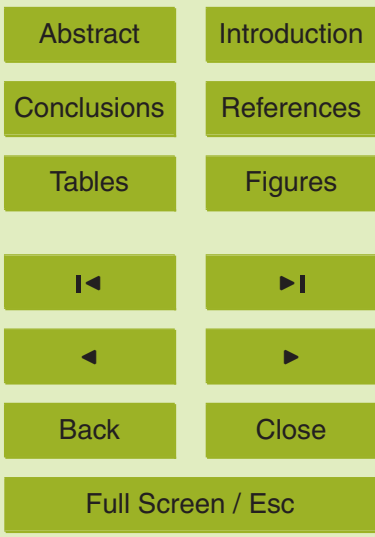

Printer-friendly Version

Interactive Discussion 
BGD

7, 5517-5555, 2010

Impact of climate and land use/cover changes on the carbon cycle in China

Z. Gao et al.

Table 3. Changes in NPP, HR, NEP, VEGC and SOC occurring in the LUCC area (unit: PgC).

\begin{tabular}{lcccrrr}
\hline LULC & NPP & HR & NEP & VEGC & SOC & Total C \\
\hline 2000 & 0.0510 & 0.0520 & -0.0007 & 0.131 & 1.068 & 1.200 \\
1990 & 0.0487 & 0.0490 & -0.0002 & 0.161 & 1.165 & 1.326 \\
Changes & 0.0020 & 0.0023 & -0.0009 & -0.030 & -0.097 & -0.126 \\
\hline
\end{tabular}




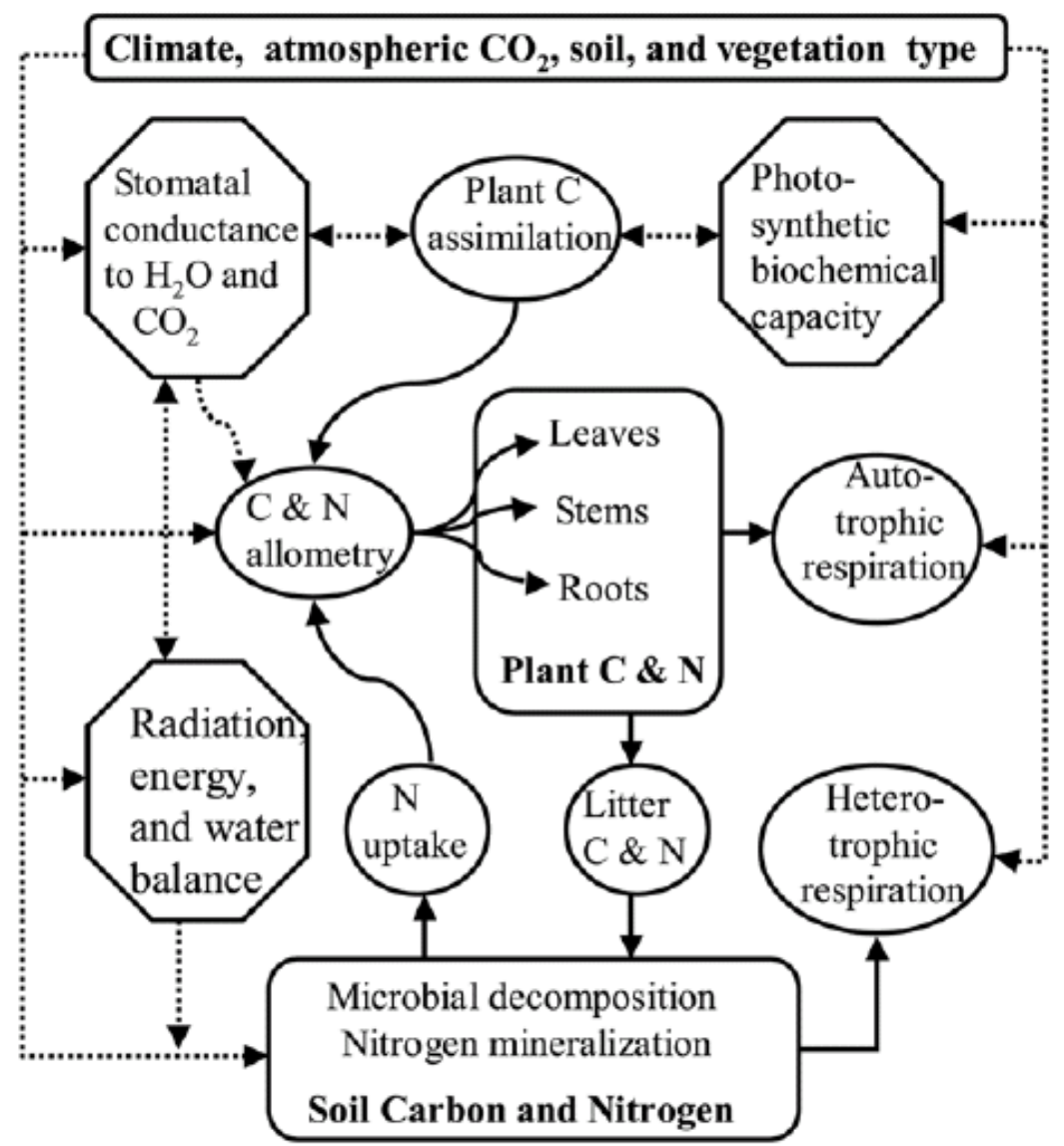

Fig. 1. A schematic representation of the model of Carbon Exchanges in the Vegetation-SoilAtmosphere system (CEVSA) (Cao et al., 1998a,b, 2002) used in this study. The solid lines are the carbon and nitrogen flows, and the dashed lines represent the effects of various factors or processes.
BGD

$7,5517-5555,2010$

Impact of climate and land use/cover changes on the carbon cycle in China

Z. Gao et al.

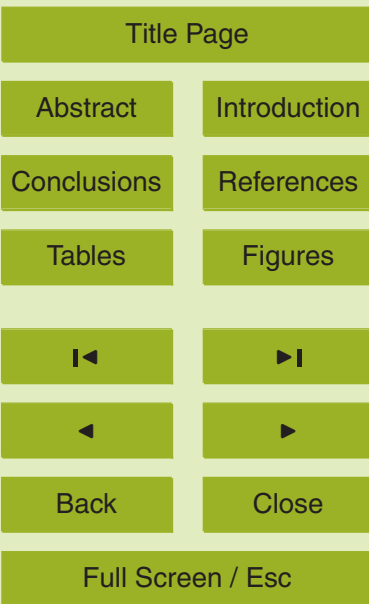

Printer-friendly Version

Interactive Discussion 

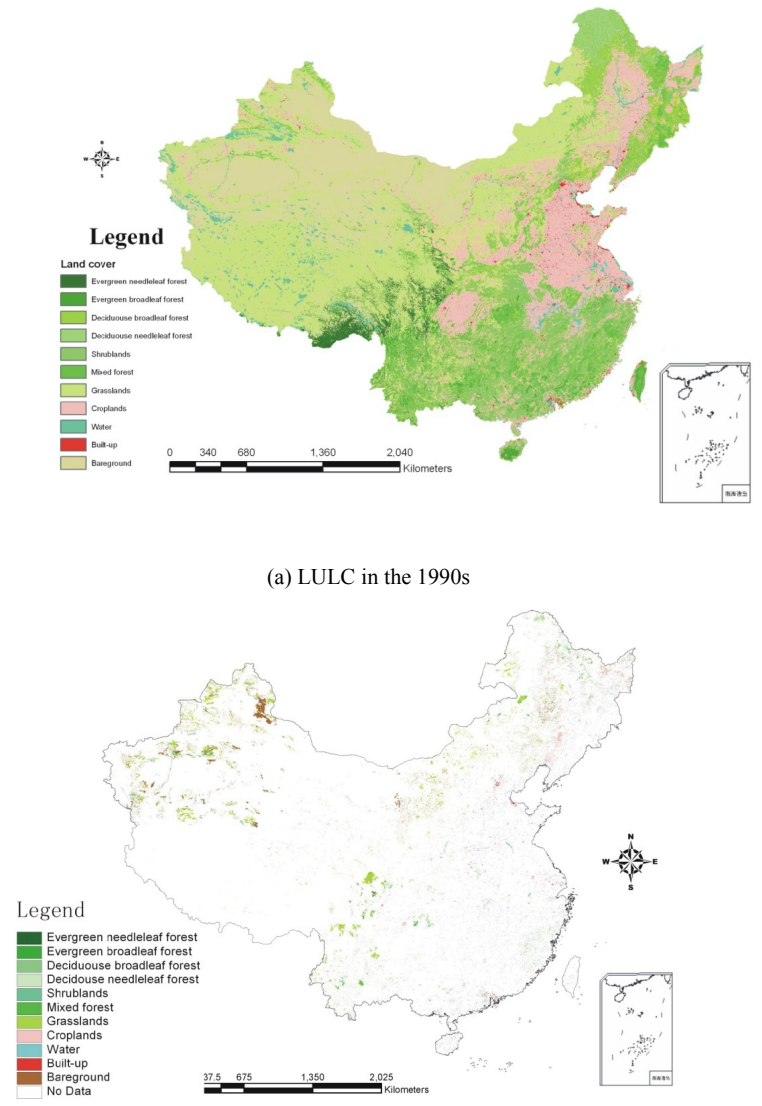

(b) The difference of LULC between 1980s and 1990s

Fig. 2. The LULC maps and dynamic changes (1990-2000).
BGD

$7,5517-5555,2010$

Impact of climate and land use/cover changes on the carbon cycle in China

Z. Gao et al.

Title Page

Abstract

Introduction

Conclusions

References

Tables

Figures

14

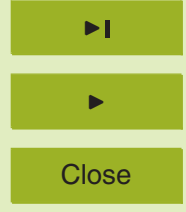

Back

Full Screen / Esc

Printer-friendly Version

Interactive Discussion 
BGD

7, 5517-5555, 2010

Impact of climate and land use/cover changes on the carbon cycle in China

Z. Gao et al.

\section{Title Page}

Abstract

Introduction

Conclusions

References

Tables

Figures

14

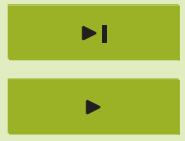

Back

Close

Full Screen / Esc

Printer-friendly Version

Interactive Discussion 


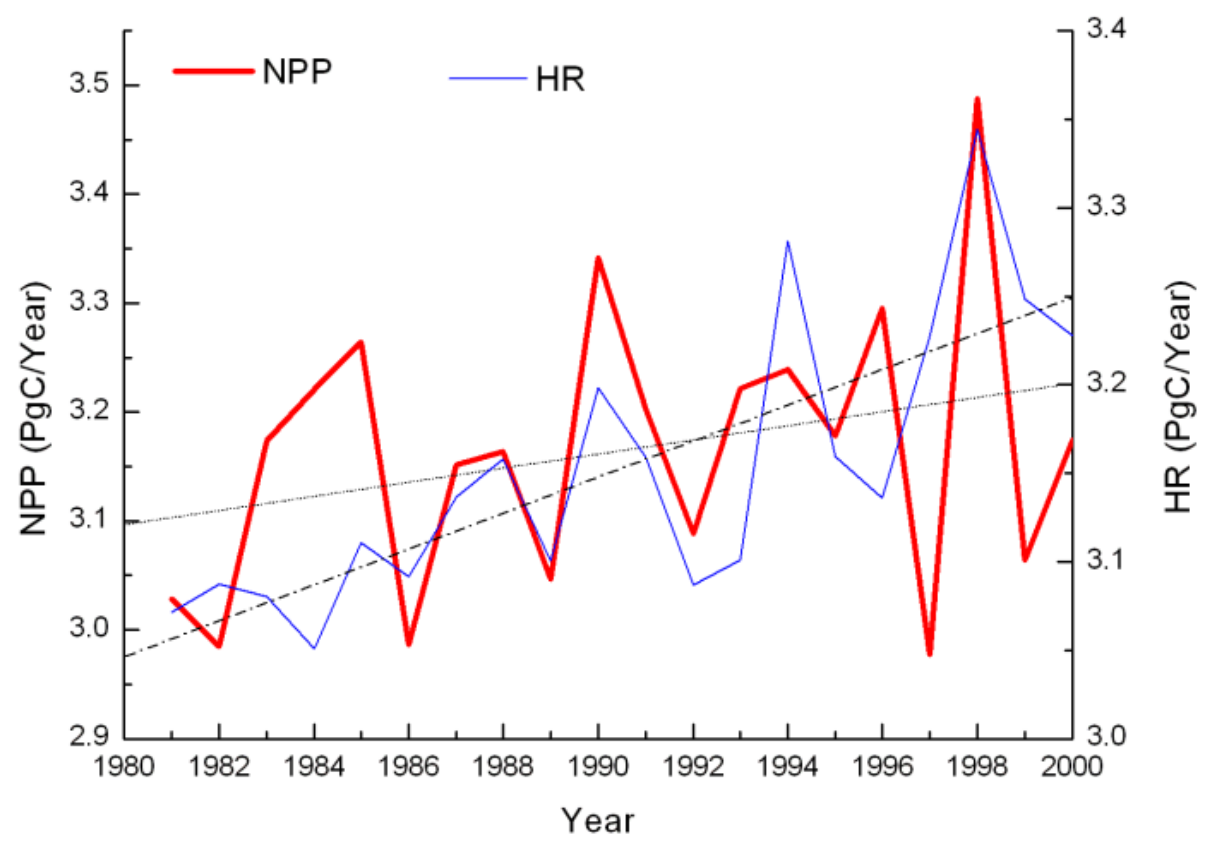

\section{Impact of climate and land use/cover changes on the carbon cycle in China}

Z. Gao et al.

\section{Title Page}

Abstract

Conclusions

Tables

14

4

Back
Introduction

References

Figures

\section{$>1$}

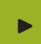

Close

Fig. 4. The decadal changes of NPP and HR.

Full Screen / Esc

Printer-friendly Version

Interactive Discussion 


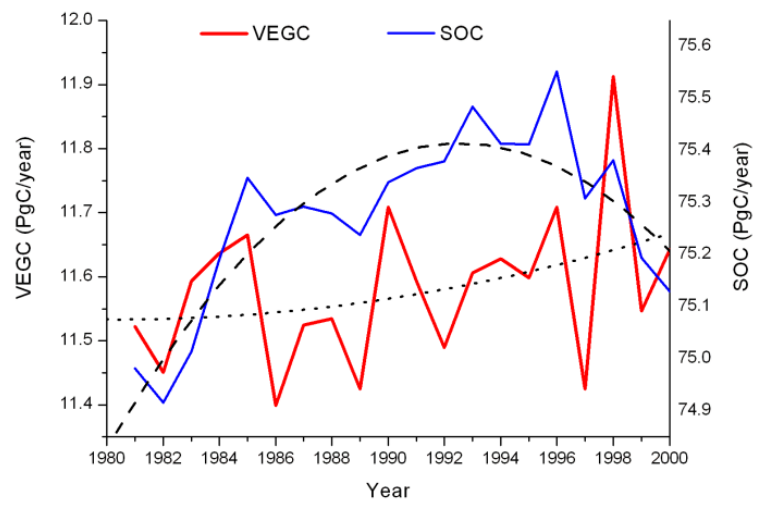

BGD

7, 5517-5555, 2010

Impact of climate and land use/cover changes on the carbon cycle in China

Z. Gao et al.

(a) VEGC versus SOC

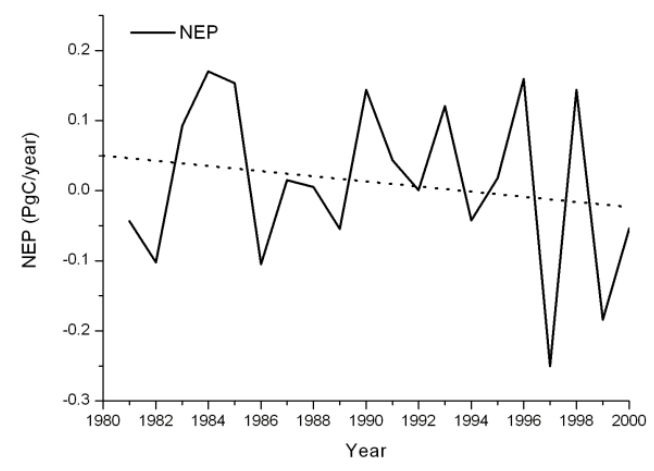

(b) Variations in NEP and its long-term trend

Title Page

Abstract

Conclusions

Tables

14

4

Back

Full Screen / Esc

Printer-friendly Version

Interactive Discussion 


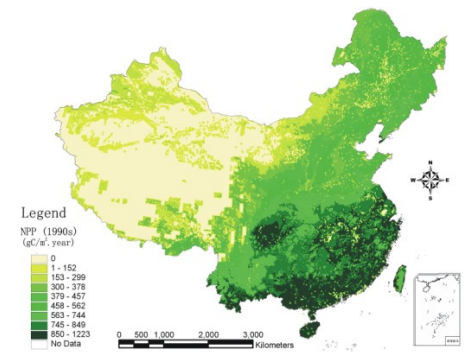

a. Spatial distribution of NPP

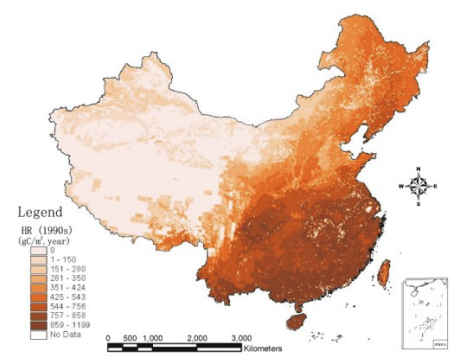

c. Spatial distribution of HR
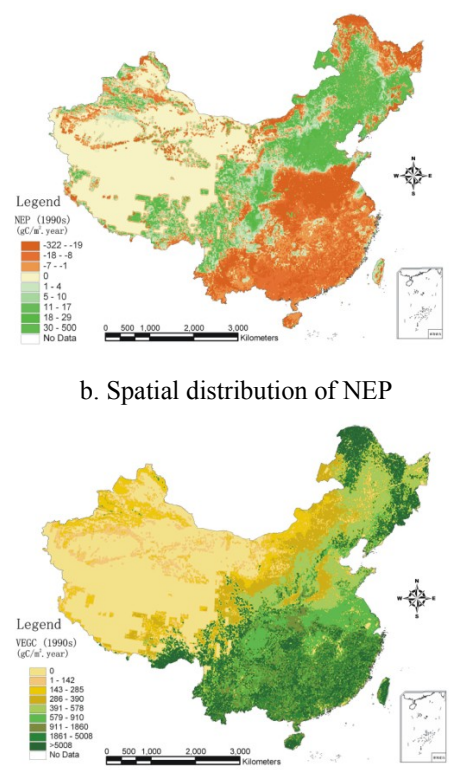

d. Spatial distribution of VEGC b. Spatial distribution of NEP

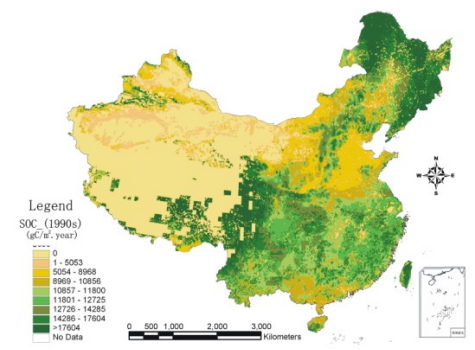

e. Spatial distribution of SOC

Fig. 6. Spatial distributions of NPP, HR, NEP and VEGC simulated based on LULC of 1990 ( $\left.\mathrm{g} \mathrm{C} / \mathrm{m}^{2} / \mathrm{y}\right)$.

\section{BGD}

$7,5517-5555,2010$

Impact of climate and land use/cover changes on the carbon cycle in China

Z. Gao et al.

\section{Title Page}

\section{Abstract}

Conclusions

Tables

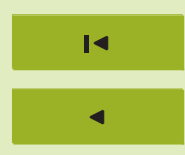

Back
Introduction

References

Figures

$\rightarrow 1$

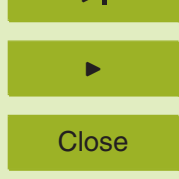

Full Screen / Esc

Printer-friendly Version
Interactive Discussion

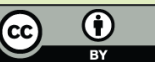




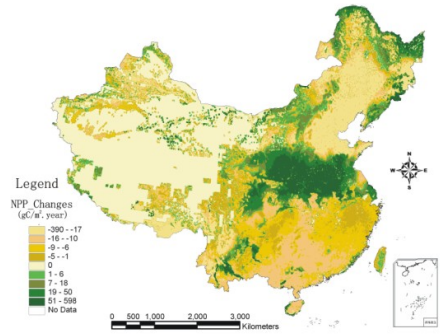

a. Spatial variations of NPP

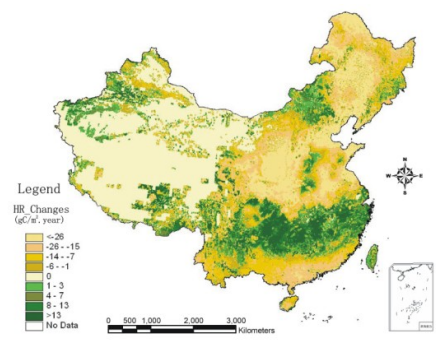

c. Spatial variations of HR

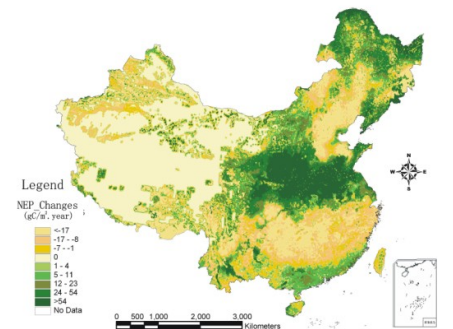

b. Spatial variations of NEP

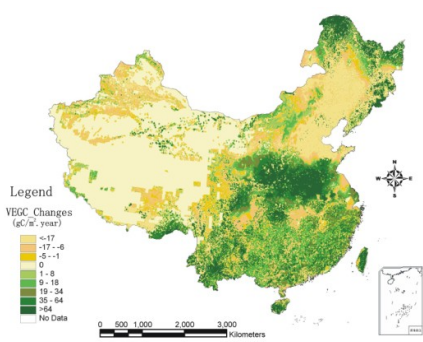

d. Spatial variations of VEGC

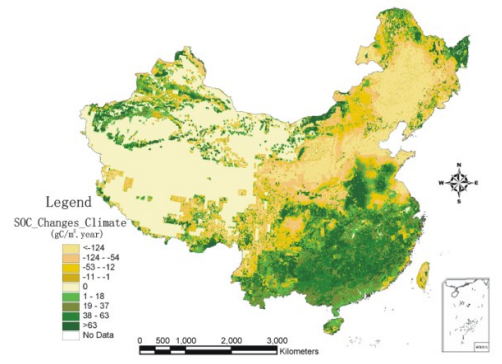

(e) Spatial variations of SOC

Fig. 7. Spatial variations of NPP, HR, NEP and VEGC changes under the influence of climate change $\left(\mathrm{g} \mathrm{C} / \mathrm{m}^{2} / \mathrm{y}\right)$.

BGD

$7,5517-5555,2010$

Impact of climate and land use/cover changes on the carbon cycle in China

Z. Gao et al.

\section{Title Page}

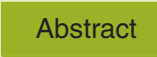

Introduction

Conclusions

References

Tables

Figures

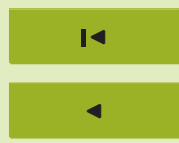

$\rightarrow 1$

Back

Close

Full Screen / Esc

Printer-friendly Version

Interactive Discussion 
BGD

$7,5517-5555,2010$

\section{Impact of climate and land use/cover \\ changes on the carbon cycle in China}

Z. Gao et al.

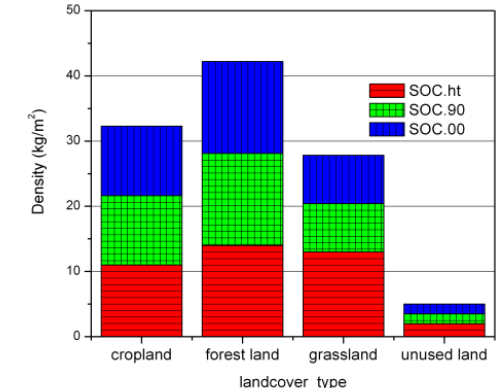

a. The estimated soil carbon density in 1990 and 2000

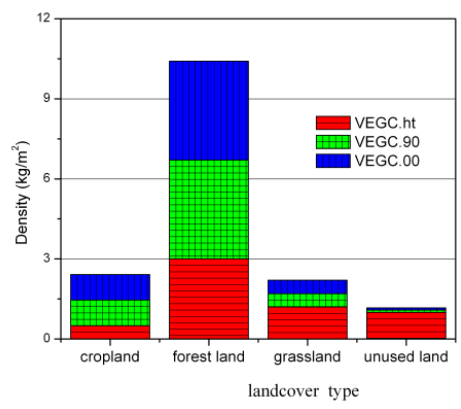

b. The estimated vegetation carbon density in
Fig. 8. Comparison of the carbon densities against the literature estimated for the year 1990 and 2000.

\section{0 and 2000}




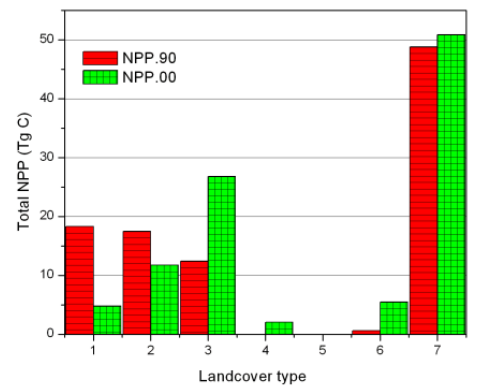

a. The NPP changes in response to LUCC

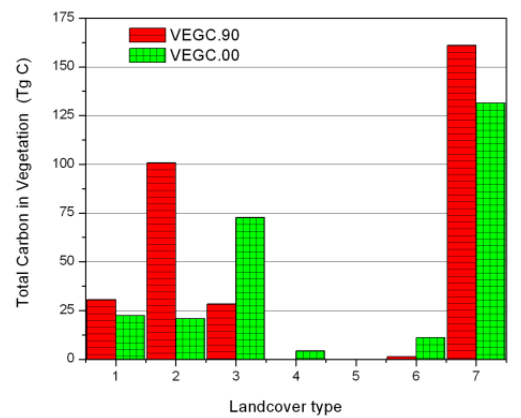

c. The VEGC change in response to LUCC

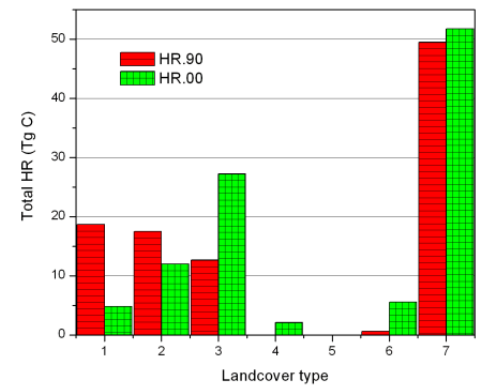

b. The HR changes in response to LUCC

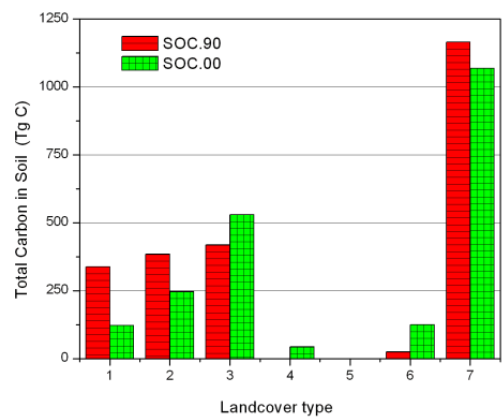

d. The SOC change in response to LUCC

Fig. 9. The changes in carbon flux and storage under LUCC (1: cropland, 2: forest land, 3: grassland, 4: water body, 5: constructed land, 6: unused land, 7: total) (unit: $\mathrm{g} \mathrm{C} / \mathrm{m}^{2} / \mathrm{y}$ ).

\section{BGD}

$7,5517-5555,2010$

Impact of climate and land use/cover changes on the carbon cycle in China

Z. Gao et al.

\section{Title Page}

\section{Abstract}

Introduction

Conclusions

References

Tables

Figures

14

4

Back

Close

\section{Full Screen / Esc}

Printer-friendly Version

Interactive Discussion 


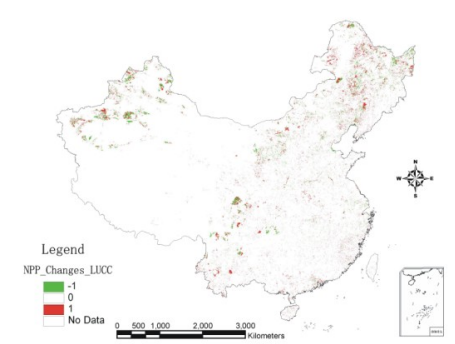

a. The impact of LUCC on NPP distribution

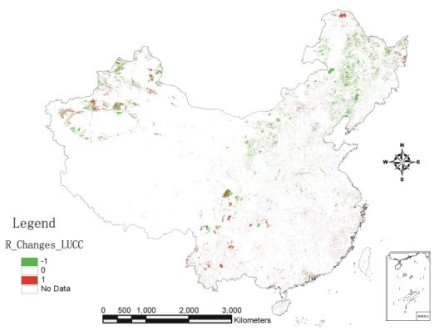

c. The impact of LUCC on HR distribution
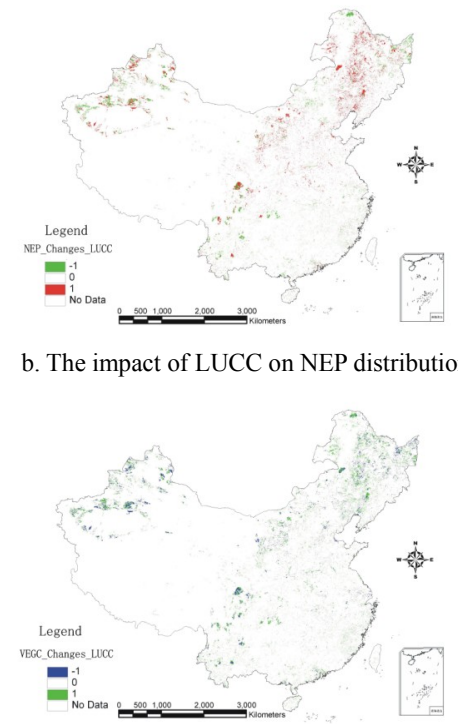

d. The impact of LUCC on VEGC distribution b. The impact of LUCC on NEP distribution

BGD

$7,5517-5555,2010$

Impact of climate and land use/cover changes on the carbon cycle in China

Z. Gao et al.

\section{Title Page}

\section{Abstract}

Introduction

Conclusions

References

Tables

Figures

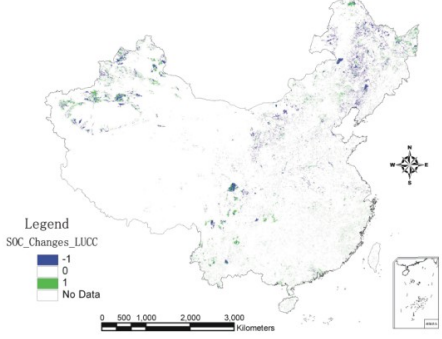

e. The LUCC impact on SOC distribution

Fig. 10. The impact of LUCC on NPP, HR, NEP, VEGC, and SOC (Legend: -1: decrease, 0 : unchanged, 1 : increase).

\section{4}

4

Back

Full Screen / Esc

Printer-friendly Version

Interactive Discussion 